\title{
A Community-Response Approach to Mental-Health and Substance-Abuse Crises Reduced Crime
}

\author{
Thomas S. Dee* \\ Jaymes Pyne* \\ Stanford University
}

June 10, 2022

\begin{abstract}
Police officers often serve as first responders to mental-health and substance-abuse crises. Concerns over the unintended consequences and high costs associated with this approach have motivated new emergency-response models that augment or completely remove police involvement. However, there is little causal evidence evaluating these programs. This pre-registered study presents quasi-experimental evidence on the impact of an innovative "community response" pilot in Denver that directed targeted emergency calls to health-care responders instead of the police. We find robust evidence that the program reduced reports of targeted, less serious crimes (e.g., trespassing, public disorder, resisting arrest) by 34 percent and had no detectable effect on more serious crimes. The sharp reduction in targeted crimes reflects both that health-focused first responders are less likely to report individuals they serve as criminal offenders and the program's spillover benefits (e.g., reducing crime during hours when it was not in operation).

*Corresponding authors. Emails: tdee@stanford.edu; pyne@stanford.edu. Authors contributed equally to this manuscript.
\end{abstract}


Police often serve as first responders to emergency calls involving nonviolent individuals in mental health distress or suffering from alcohol or drug abuse. This procedural norm has been the subject of debate and criticism for two broad reasons. One is that serving as first responders to calls involving mental health crises is a substantial drain on scarce police resources and comes with heavy human and social costs, even in the absence of police violence and use of lethal force (1-4). Police currently spend more time responding to such "low-priority" calls than to any other type of emergency call $(5)$. Recent estimates $(6,7)$ suggest that a quarter to two-thirds of the emergency calls involving disorder, mental health, medical, and noncriminal calls to which police currently respond could instead be directed to mental health crisis experts and other first responders (i.e., a "community response" model). Those charged with minor offenses such as loitering, making false statements, and vandalism cost the criminal justice system roughly $\$ 500$ to $\$ 600$ per offense and come with even higher additional social costs (8). The potential reallocation of resources away from a police response and toward mental health supports is often a part of current initiatives to "defund the police" $(7,9,10)$.

Second, having armed and uniformed police as first responders to a mental health or substance abuse crisis may increase the likelihood of costly outcomes and inappropriate care. Individuals living with serious mental illness are no more prone to violence or unpredictability than the general population $(11,12)$. However, having police officers as first responders to a mental health crisis can result in unnecessarily violent and tragic outcomes $(13,14)$. Recent news coverage (15-17) has drawn public attention to particularly shocking incidents in which responding police officers seriously harmed or killed a person in mental health distress (18). More generally, having the police respond to such incidents can be costly and unproductive because police are more likely than mental health clinicians to direct individuals experiencing a mental health episode to the criminal justice system rather than to the appropriate health care (13). 
In response to these concerns, municipalities across the country have begun to pilot targeted reforms. The two most common approaches augment the capacity of police officers to serve as effective first responders to individuals experiencing mental health crises. The "crisis intervention team" (CIT) approach emphasizes training police officers how to respond to individuals in crisis and connect them with appropriate services (19). In contrast, the "co-response" model involves structuring explicit partnerships between police departments and professional mental health practitioners so they can simultaneously respond to incidents involving mental health crises (20-23). A third and less common approach either delays or foregoes on-scene police involvement in certain incidents by relying on "a new branch of civilian first responders known as 'Community Responders"' (5). These so-called community response programs can use first responders with expertise in a breadth of social service support and establish a triage protocol under which emergency calls for mental health crises are first addressed by a health team (e.g., a mental health crisis interventionist and a paramedic) before deciding whether to request direct police involvement (5).

The momentum behind the adoption of programs that seek to improve police interactions with individuals in mental health crises has motivated multiple empirical studies that seek to understand their impact. Several systematic reviews and metaanalyses have synthesized this evidence, particularly focusing on the more common CIT and co-response models (20, 24-28). In general, this empirical literature suggests that these program innovations have beneficial effects by reducing arrests and detention rates, but evidence is mixed on whether these programs are cost-effective. However, the research designs used in these studies (e.g., case notes, qualitative and descriptive studies, before/after comparisons, and cross-sectional comparisons) generally do not support credible causal inference. For example, one recent prominent review concludes that “... we caution against drawing conclusions related to causality based on these findings" (27). There is a similar lack of evidence on the impact of less common community response models. Existing evaluations are typically conducted 
internally by cities, police departments, or community response teams and rely on descriptive evidence of the number of calls taken by the few community response units operating across the United States (5).

Furthermore, critics warn that initiatives to reduce police involvement in response to emergency calls will "embolden the bad guys" (29) and unintentionally increase the prevalence of more serious criminal offenses (30-33). This belief, often referred to as the "broken windows" theory in which police response to low-priority criminal violations prevents more serious ones, underscores the need for research studies that can provide credibly causal estimates of the impact of these innovative programs both on the focal, less serious crimes they target and on more serious offenses. However, the debate on defunding police has a limited causal basis, having "proceeded without adequate research about either the scale or nature of issues that the police handle or the potential consequences of the proposed reform efforts" (7). This study seeks to provide such evidence by examining the impact of a community response program recently piloted in the City and County of Denver, Colorado through the independent analysis of a preregistered, quasi-experimental design coupled with several complementary robustness checks.

\section{The Support Team Assistance Response pilot program}

The Support Team Assistance Response (STAR) program in Denver provides a mobile crisis response for community members experiencing problems related to mental health, depression, poverty, homelessness, and/or substance abuse issues. The STAR response consists of two health care staff (i.e., a mental health clinician and a paramedic in a specially equipped van) who provide rapid, on-site support to individuals in crisis and direct them to further appropriate care including requesting police involvement, if necessary. The design of the STAR program is based on the Crisis Assistance Helping Out On The Streets program developed in Eugene, Oregon (34). 
STAR began operations on 1 June 2020 for a designated 6-month pilot period. During this period, STAR limited its operations to selected 911 calls for assistance in eight purposefully chosen police precincts (i.e., out of the city's 36 precincts), where the need for STAR services was anticipated to be the greatest. The pilot area was in the central downtown area of Denver (fig. S1) and largely represents neighborhoods with residents who are more affluent, educated, and white than the city as a whole (see table S1). However, all but one of the neighborhoods in the STAR pilot service area are also designated by the city as "displacement-vulnerable" areas, rapidly gentrifying city spaces where poor and otherwise at-risk residents are being pushed out (35). In such contested urban spaces, there are often increasing demands on police to conduct "rabble management" that addresses overwhelmingly nonviolent incidents (36-39).

Operators responding to 911 calls for assistance dispatched STAR staff to eligible incidents that were located in the designated police precincts and during the program's hours of operation (Monday to Friday, 10 a.m. to 6 p.m.). The identification of emergency calls eligible for STAR services relied on two specific screening criteria. First, the incident had to designate at least one of several codes: calls for assistance, intoxication, suicidal series, welfare checks, indecent exposure, trespass of an unwanted person, and syringe disposal (40). Second, to dispatch the STAR van, there needed to be no evidence that the incident involved serious criminal activity, such as weapons, threats, or violence, or serious medical needs. The STAR team also responded to calls from uniformed police to engage with community members in crisis and initiated engagement in the field on their own. Over the 6-month pilot period, the STAR team responded to 748 incidents or nearly 6 incidents per 8-hour shift. Roughly a third of calls to STAR occurred at the request of responding police, while the rest were due to a direct 911 dispatch or to the STAR team responding independently to a field observation-none of which required a call to police for assistance or for a response to a criminal offense (41).

\section{Measuring STAR impacts on crime}


We identify the impact of the STAR program on STAR-related and STARunrelated measured crime using "difference in differences" (DD) and "difference in difference in differences" (DDD) designs that effectively rely on before-after comparisons across treated and comparison precincts (i.e., along with the evidence from several complementary robustness checks and alternative estimation procedures). To identify the impact of the STAR program, we consider all criminal offenses reported by the City and County of Denver through data collected as part of their participation in the federal National Incident-Based Reporting System (NIBRS). These data include calls for police assistance that escalated to offenses reported by the police regardless of whether they led to formal charges (including arrest) or whether the STAR team was dispatched or responded to the call. However, offenses are not differentiated by whether they led to an arrest or some other offense-related outcome (e.g., a citation). We also do not have access to such arrest and citation data and recognize their possible confounding. That is, such data may be missing (e.g., valid criminal offenses where no one is apprehended and, therefore, there is no arrest or citation) and may be confounded further by police and prosecutorial discretion around whether to sustain an arrest or citation for a given offense.

Before our analysis, we coded each offense as directly related to STAR operations (e.g., disorderly conduct, trespassing, alcohol, and drug use) or not (e.g., burglary; see tables S2 and S3 and Supplementary Text for details). For this focal outcome (i.e., lower-level reports of criminal offenses), we expect either the STAR team or the police to often engage the individual in question. If a criminal offense is recorded during such service calls, then it implies either an arrest or a citation. If no crime is recorded, then it implies either a field determination that no criminal offense occurred or a discretionary decision not to record such low-level criminal offenses (e.g., trespassing).

The impact of the STAR program on the frequency of these offenses is theoretically uncertain. For example, to the extent police who respond to mental health 
and substance abuse incidents consistently direct individuals in crisis to health care services without also identifying them as low-level criminal offenders, the overall effects of the STAR program would be muted—or even null. The Denver police have participated in CIT training designed to support their capacity to identify individuals who need mental health support and to direct those individuals to appropriate care. Because the comparison condition in this study consists of such CIT-trained police as first responders, the introduction of the STAR team could, in theory, have small or nonexistent effects on recorded crime.

This study provides quasi-experimental evidence on the overall (i.e., "reduced form") effect of STAR's community response approach on the number of recorded crimes. With respect to reducing recorded criminal offenses, the STAR program's overall impact could reflect the combination of two broad, underlying mediating mechanisms that merit careful emphasis. One involves program-induced reductions in the recording of existing criminal offenses, while the other concerns reductions in actual crime.

The first mediating mechanism would occur when STAR first responders simply do not record an existing criminal offense (e.g., substance abuse and disorderly conduct) that police officers would record when responding to a given incident. This reporting mechanism has clear empirical relevance given that (i) under NIBRS procedures, law enforcement officials (i.e., not STAR staff) identify and report criminal offenses and (ii) the program data from the period we study indicate that STAR staff did not involve police in their service calls (41). However, this reporting mechanism also reflects an impact of social consequence. Specifically, it implies that, when STAR staff replace police as first responders, individuals in mental health or substance abuse crises may be more likely to receive health care and are less likely to be identified as criminal offenders (i.e., implying arrests or citations).

A second class of mediating mechanisms underlying STAR's overall impact also reflects effects of clear policy relevance. Specifically, there are several reasons that the 
STAR program could also lead to a genuine reduction in the prevalence of criminal offenses. First, this would occur if the STAR team is more effective than police in implementing de-escalation tactics that reduce the likelihood of further criminal acts (e.g., assaults) when responding to an incident $(42,43)$. In addition, the STAR team may prevent crime in the near future by reducing recidivism among individuals in crisis. Individuals experiencing mental health or substance abuse crises are quite likely to reoffend (42). However, STAR's targeted provision of health care could reduce the prevalence of such future incidents that would otherwise be recorded as crimes.

In addition, there are at least two other potential "spillover" mechanisms by which the STAR program reduces crime. One is the possibility that the presence of the STAR program in a precinct improves police officers' implementation of their CIT training. This can occur if officers are more likely to call the STAR team when in need or if they better implement their own CIT training by independently directing individuals in mental health crises to health care responders rather than the criminal justice system when they know STAR is active in their precinct. Another possible, although uncommon, mechanism happens when STAR staff initiate a response in the field. If STAR staff happened to observe an individual clearly in need of their services, then they would sometimes respond without evidence that a crime had yet occurred and without direction from 911 dispatchers or on-scene police officers (41).

A reduced-form analysis similar to the one used in this study cannot exactly decompose STAR's overall impact on crime into the components attributable to these varied mechanisms (e.g., genuine crime reductions and the differential recording of individuals in mental health crises as not having committed criminal offenses). However, we do discuss two pieces of ancillary evidence that indicate whether STAR's overall impact partly reflects lower levels of actual crime in addition to the reduced reporting of criminal offenses. First, we provide direct evidence for genuine crime reductions by examining the impact of the STAR program on crimes occurring outside STAR's operating hours (e.g., spillover benefits due to reduced recidivism). Second, 
we compare the total crime reduction attributable to STAR to the amount that would be expected if STAR's effects only operated through its service calls. We construct this expected number by multiplying the number of STAR service calls conducted during the pilot period by the number of criminal offenses typically recorded in such criminal incidents during the pretreatment period.

\section{RESULTS}

As an initial and unrestrictive way to visualize the impact of the STAR program, Fig. 1 shows precinct-level maps that illustrate the before-after changes in measured crime by offense type. These crime measures consist of all incidents reported to the Denver police department that they then record as involving criminal activity, regardless of whether an arrest occurred. Our main analysis focuses on monthly, precinct-level data for the period 6 months before and after the start of the STAR pilot program (i.e., December 2019 to November 2020 in 432 precinct-month observations), differentiating offenses as STAR-related and STAR-unrelated offenses (see Supplementary Text for details). These maps show that treated precincts experienced sharp, comparative declines in STAR-related crimes but not in those crimes not directly related to STAR services.

Estimates based on the DD and DDD designs (i.e., Eqs. 1 and 2) allow us to estimate these effects directly and to condition on fixed effects unique to precincts and months. Figure 2 displays the key estimates (and corresponding 95\% confidence intervals) based on these quasi-experimental specifications. For our main confirmatory hypothesis, the DD estimate indicates that the STAR program led to large and statistically significant reduction in the targeted measured crimes $(\mathrm{b}=-0.41, \mathrm{SE}=$ $0.07, \mathrm{t}=-6.09, \mathrm{P}<0.001)$. This estimated impact on the natural log of STAR-related crimes implies that the program reduced these targeted crimes by $34 \%$ [i.e., (e $(-0.41)$ $-1) \times 100]$. By contrast, the estimated effect of the STAR program on measured crimes that were not directly related to STAR services was comparatively small and 
statistically insignificant $(\mathrm{b}=-0.05, \mathrm{SE}=0.04, \mathrm{t}=-1.18, \mathrm{P}=0.245)$. This finding suggests that the targeted fielding of mental health professionals as first responders did not increase the frequency in reporting more serious criminal incidents in treated precincts. This null result can also be understood as affirming the causal warrant of the DD design by indicating that there were not unobserved and confounding determinants of crime unique to the precincts and months associated with the STAR pilot, a finding consistent with the causal warrant of the DD design. The DDD specification (i.e., Eq. 2) leverages these comparative results by using the data on crimes unrelated to STAR operations as a comparison condition unique to each precinct-month observation. The DDD estimate similarly implies that STAR operations led to a large and statistically significant reduction in reports of targeted crimes $(\mathrm{b}=-0.36, \mathrm{SE}=0.05, \mathrm{t}=-6.64, \mathrm{P}<0.001)$. This DDD estimate suggests that the STAR program led to a 30\% reduction [i.e., $(\mathrm{e}(-0.36)-1) \times 100$ ] in STARrelated offenses (see table S4 for full numeric results).

Figure 3 illustrates the key estimates from event-study DD specifications that allow for effects unique to treated precincts in each month before and after the onset of STAR operations (see Supplementary Text for specification details). The bottom red line in Fig. 3 represents the point estimates from an unrestrictive event-study specification that examines the treatment comparison difference in reports of STARtargeted crimes in the months before and after program implementation (see table S5 for numeric results). The top yellow line presents similar estimates based on STARunrelated offenses. These results indicate that, in the months before STAR operations, the treated and comparison precincts had similar trends in STAR-related crimes. More formally, we do not reject the hypothesis that the effects on STAR-related measured crimes that are unique to treated precincts in the months before STAR operations are the same as those in the comparison precincts $(\mathrm{P}=0.71)$. These results are consistent with the "parallel trends" assumption of the DD design and with a causal interpretation of the results based on Eq. 1. The event-study estimates in Fig. 3 also 
illustrate the distinct drop in STAR-related crimes associated with the onset of STAR services, as well as the comparative absence of any relationship with the prevalence of crimes that are not directly related to STAR operations. Figure S2 similarly presents conditional means for each group of offenses (i.e., STAR-related and STAR-unrelated) by month for both treatment and comparison precincts, and fig. S3 shows trends in STAR-related offenses among the eight treated districts.

The Supplementary Materials presents several ancillary analyses that explore the robustness of these findings. For example, Poisson and negative binomial specifications that recognize both the count nature of the crime data and the presence of fixed effects (44) return results similar to those based on ordinary least squares estimates of Eq. 1 (table S6). The DD results presented here are also similar in specifications that rely only on when treating May 2020 as a treatment month among STAR-active precincts to allow for anticipation effects (table S6). When we remove offenses that are STAR related but not STAR targeted (i.e., simple assault, simple assault on a police officer, and disarming a police officer; see Supplementary Text for details), the static DD effect size is larger than what we report. That is, the point estimate is -0.41 when those assault offenses are included as STAR-related offenses and is -0.49 when they are not (table S6; see Supplementary Text for additional details). We also find similar levels of statistical significance when we remove police precinct 311, which is not entirely serviced by the program, and in specifications that correct for the potential finite-sample bias in the precinct-specific clustering of the error term (table S6). We also find that the results are robust when using permutationbased randomization inference (fig. S4).

Next, to test whether common seasonal changes in crime rates threaten the causal interpretation of these results, we construct parallel "placebo effect" datasets of months from December 2016 to November 2017, December 2017 to November 2018, and December 2018 to November 2019. In each time frame, we code all months in each dataset past May as a placebo "treatment" month for all STAR-active precincts. 
If these estimates indicate a consistent drop in measured crime in the STAR precincts following May of each year, then that would suggest that the main results reflect seasonal patterns rather than the implementation of the STAR pilot. Instead, results based on these data consistently suggest no statistically detectable reductions in the measured crime after June in any of these prior years. We show these prior-year placebo estimates for static DD specifications (table S6) and event studies (figs. S5 to S7).

Several additional internal validity checks detailed in the Supplementary Material provide evidence on the coronavirus disease 2019 (COVID-19) pandemic as a possible confound and related evidence that speaks more generally to the validity of the parallel-trends assumption. In particular, estimates near the bottom of table S6 indicate that the estimated effects of the STAR program are similar in specifications that only rely on data following the beginning of COVID-19 shutdown orders (i.e., March 2020 to November 2020). Second, the estimated effects of the STAR program are also similar when based on generalized synthetic control design (45) and comparative interrupted time series design (46) that explicitly accommodate the presence of preexisting trends across treatment and comparison precincts (see table S7 for results and Supplementary Text for details on these procedures).

Last, the Supplementary Materials also presents analyses that explore the potential heterogeneity in these results. For example, the event-study results (Fig. 3) suggest that the impact of the STAR program grew over time. However, estimates based on a semi-dynamic DD specification cannot reject the hypothesis that the impact of the STAR program is the same in each of the 6 months of operation $(\mathrm{P}=$ 0.91; table S5). In addition, in table S6, we show that DD specifications that allow for spatial spillover effects of the STAR program in geographically adjacent districts indicate that the estimated effect of STAR operations on neighboring precincts was small and statistically insignificant. However, there do appear to be meaningful temporal spillover benefits of the STAR program within treated precincts. Specifically, 
the reductions in STAR-related measured crimes in treated precincts also occurred during days of the week and times when the program was not active (table S6). This pattern is consistent with the hypothesis that the STAR program provided helpful services to individuals in crises that were somewhat persistent rather than brief and episodic. However, these temporal spillovers do not extend to precincts adjacent to those with STAR operations.

There remains the possibility of spatiotemporal spillover. For example, "near repeat" crime is the phenomenon in which criminal incidents increase near to and shortly after the occurrence of a crime (47). However, our analysis relies on precinctlevel panel data (i.e., the level at which STAR was implemented), while spatiotemporal spillovers are likely to occur on finer spatial levels. Even so, we estimated effects of the STAR program on STAR-adjacent precincts during STAR-active and STARinactive time periods. The results are consistently null (see table S6). While these findings indicate that there are no cross-precinct spillovers, we note that this is not necessarily evidence against the near-repeat phenomenon. Furthermore, using the police categorization of crimes suggests that STAR operations led to a $14 \%$ reduction in overall crimes (table S8) and that these reductions were concentrated in three STARrelated categories (i.e., alcohol and drugs, disorderly conduct, and other crimes against persons).

\section{DISCUSSION}

Police officers in the United States currently spend a substantial amount of their time responding to nonviolent emergency calls for assistance, which often involve individuals experiencing mental health or substance abuse crises. However, police officers are not extensively trained to assist with such crises and most believe that such incidents are outside of their professional purview (48, 49). As a result, emergency calls for assistance may be engaged as criminal violations, sometimes with unnecessarily violent or even tragic consequences, when they can be better addressed 
as health issues. The widespread recognition of this issue has motivated initiatives to improve police training and cooperation with health professionals (e.g., CITs and coresponse models). A less common but more marked innovation for responding to nonviolent individuals in crisis is to delay or forego police involvement by sending a health care team as first responders (i.e., a community response model). Although each of these programmatic models is grounded in a sensible theory of change, there is not currently credible, causal evidence on their effects $(5,7,20,24-26,28)$.

In this study, we have presented the results of a preregistered quasiexperimental design that examined the effects on crime of a community response program that dispatched a mental health clinician and paramedic to nonviolent emergency calls rather than first sending police. STAR is a community response program that operated as a pilot program for 6 months and provided service within eight police precincts in Denver's central downtown area. Drawing on data of calls for service that escalate to criminal offenses recorded by police officers (i.e., incidents leading an arrest or citation), from December 2019 to November 2020, we have used a DD model that effectively compares the changes in police-recorded criminal offenses both before and after the pilot program and across the treated and untreated precincts. We complement the results of this preregistered design with a variety of robustness checks (e.g., alternative approaches to estimation and inference and falsification exercises based on prior years of data). We also examined whether STAR operations influenced the frequency of more serious offenses that were not directly targeted by the program and found no discernable impact.

We find that the program led to large and sustained reductions in reports of STAR-related offenses in treated precincts, while unrelated offenses over the treatment period changed little in those same police precincts (Fig. 2). Our comparative estimates suggest that the service reduced the number of STAR-related offenses in treated precincts by $34 \%$ over the 6 months of the pilot phase. While the average number of STAR-related offenses in our precinct-month sample is 34 (see 
table S3), the frequency of these measured offenses in STAR-active precincts before treatment is much higher (i.e., averaging 84.3 offenses per precinct-month from December 2019 to May 2020). This impact estimate implies that the STAR pilot program prevented nearly 1400 criminal offenses within the eight participating precincts and the 6 months of operation (i.e., $84.3 \times 0.34 \times 8 \times 6=1376$ ). This program-induced reduction in measured offenses is broadly consistent with the scale of STAR operations. Specifically, the STAR team responded to 748 calls during our study window. At baseline (i.e., during the pretreatment period), each STAR-related incident resulted in an average of 1.4 recorded offenses in treated precincts. This suggests that we should expect 748 field calls by STAR staff to result directly in just over 1000 fewer recorded offenses (i.e., $748 \times 1.4=1047$ ).

The overall (i.e., reduced form) estimated impact of the STAR program (i.e., 1376 fewer criminal offenses) reflects the simultaneous influence of two distinct, broad, and policy-relevant mechanisms. One is due to STAR first responders providing health care to individuals in mental health or substance abuse crises simply not recording them as low-level criminal offenders subject to arrest or citation. The second mechanism is due to actual reductions in crime. The empirical relevance of these two complementary mechanisms cannot be exactly identified. However, the fact that the total reduction in criminal offenses attributable to STAR (i.e., 1376) clearly exceeds the highest number of criminal offenses likely to have been confronted by STAR staff (i.e., 1047) suggests that the STAR program reduced actual crimes. In addition, the evidence that the STAR program reduced the number of low-level criminal offenses during hours when the program was inactive (e.g., reducing recidivism among individuals in crisis) provides direct support for the existence of this underlying mechanism.

Last, we find that STAR's operation during the pilot phase did not increase reports of more serious or violent offenses. Under the broken windows theory, less police enforcement of low-priority criminal violations will increase the prevalence of more 
serious and violent criminal offenses being recorded (32). Our evidence suggests that this was not the case in Denver's treated precincts. The absence of such an impact also provides an indirect validation of our main finding by indicating that there were not confounding trends in crime unique to treated precincts. The DDD estimates we present formalize this robustness check but rely on additional assumptions (e.g., there is no crime-fighting benefit to having STAR in a precinct). Our findings' interpretation as robustness checks is thus only secondary to the standalone finding of null effects on serious crimes as a test of prior criminological theory.

The evidence in this study indicates that the STAR community response program was effective in reducing police-reported criminal offenses (i.e., both reducing the designation of individuals in crisis as criminal offenders and reducing the actual level of crime). These results provide a compelling motivation for the continued implementation and assessment of this approach. However, successfully replicating the STAR program is likely to rely on key implementation details such as the recruitment and training of dispatchers and mental health field staff as well as the successful coordination of their activities with the police. Furthermore, the generalizability of the community response approach to a broader set of potentially preventable charges is uncertain and a design feature worthy of further study. There are also additional details about programs such as STAR that merit further investigation and clarification. For example, we are unsure of whether the existence of STAR may have increased the trust and the willingness of community members to call 911. However, we note that such an effect is likely to imply that our estimates underestimate the true effect of the STAR program. That is because increase in trust and willingness to call 911 is likely to increase measured crime in the short run as some of these calls would result in police engagement regardless of arrest status. Future studies may also consider the effects of programs like STAR on health-related outcomes, such as access to health services (e.g., counseling and therapy) and related measures of well-being. 
Another important policy consideration is its cost-effectiveness. The total cost of the 6-month STAR pilot program was $\$ 208,141$ (50). One useful way to frame this public outlay is to note that the corresponding reduction of 1376 offenses implies a cost of $\$ 151$ per offense reduced. To put this in perspective, the available estimates (8) suggest that the direct criminal justice cost for a minor criminal offense (e.g., imprisonment and prosecuting) averages \$646 (in 2021 dollars). In other words, the direct costs of having police as the first responders to individuals in mental health and substance abuse crises are over four times as large as those associated with a community response model. A fuller reckoning of the costs and benefits associated with community response models would also include the costs and benefits associated with any health care brokered by the first responders. For example, police officers may be more likely than community responders to direct individuals in crisis to comparatively expensive emergency room care or to no care at all. Nonetheless, the results presented here suggest that community response models merit careful consideration as a highly cost-effective way to reduce police engagement with nonviolent individuals in crisis and to instead respond with appropriate health care.

\section{MATERIALS AND METHODS}

We collected counts of measured criminal offenses using data made publicly available by the City and County of Denver, Colorado through their Open Data Catalog (ODC) and based on the NIBRS. Because Denver's reporting is NIBRScompliant, a mere civilian call is not, by itself, sufficient to imply that a criminal offense is registered. Specifically, the NIBRS User Manual notes that "Participation in NIBRS requires law enforcement agencies to report certain facts about each criminal incident coming to their attention within their jurisdictions." However, because at least some calls will involve a complaint without clear criminality, they will not rise to the level of a "criminal incident coming to their attention." Thus, not every complaint or incident 
investigated by police will result in an offense being recorded in our data-instead, only those incidents that result in an arrest or citation are recorded as offenses.

Our coding identifies the types of reported offenses the STAR program would conceptually be expected to reduce (i.e., "STAR-related" offenses) rather than just the kinds of incidents the program targets. "Disarming a peace officer" is an illustrative example of the distinction between STAR-related and STAR-targeted offenses. The dispatch protocol would not send out a STAR team in response to such an offense (i.e., it is not STAR-targeted). However, this is exactly the sort of offense that might be reduced by having mental health specialists as first responders rather than police (i.e., it is STAR-related).

However, there are differences between the data reported to NIBRS and what is reported on Denver's ODC that we use here. That is, NIBRS records all serious incidents such as homicide and arson but only reports records of arrests made for less serious offenses such as the STAR-related ones that are our focus here. Conversely, we have confirmed through correspondence with M. Lunn, the Manager of Strategic Initiatives for the Denver Police Department, that their data record not only those crimes resulting in arrests or formal charges (i.e., ones involving subsequent prosecutorial decisions) but also all criminal incidents recorded by the police. To that end, our main results identify program-induced reductions in substantiated criminal incidents identified by or reported to the police. Conceptually, these reductions combine the relabeling of existing behaviors that occur when individuals in crisis receive health care rather than being directed into the criminal justice system and a reduction in criminal offenses by individuals in crisis who would offend repeatedly in the absence of health care.

The ODC contains incident-level data on all criminal offenses reported to law enforcement from January 2016 to November 2020. From that data catalog, we constructed a panel dataset of criminal offenses observed in each of 36 precincts over each of 12 months for the period from December 2019 to November 2020 (i.e., 432 
precinct-month observations). This period includes the 6-month pilot phase and the 6 months before the pilot phase.

The single confirmatory hypothesis in our preregistered analysis plan (https://osf.io/nqhvf) focuses on the impact of the STAR program in a static DD specification that takes the following form

$$
\mathrm{Ypm}_{\mathrm{pm}}=\alpha \mathrm{p}+\gamma \mathrm{m}+\theta \mathrm{Spm}+\varepsilon \mathrm{pm}
$$

where Ypm is the natural log of STAR-related criminal offenses for precinct $\mathrm{p}$ in month $\mathrm{m}$. The term, Spm, is a binary indicator equal to 1 only for STARparticipating precincts observed during the period when the program was active. The coefficient of interest, $\theta$, represents the effect of the STAR program conditional on fixed effects unique to each precinct and to each month (i.e., $\alpha \mathrm{p}$ and $\gamma \mathrm{m}$, respectively). The term, $\mathrm{ppm}$, is a mean-zero error term with clustering at the precinct level. The static DD specification in Eq. 1 embeds the assumption that the STAR program implies a one-time level shift in crimes. To explore possibly timevarying treatment effects, we also report the results of "semi-dynamic" DD that unrestrictively allow for effects to vary uniquely in each of the six treatment months. In the Supplementary Materials, we also present the results based on versions of Eq. 1 that use alternative approaches to estimation (e.g., Poisson and negative binomial count data specifications) and to inference (e.g., adjustments for finite sample clustering bias and randomization inference).

This DD research design effectively compares the before/after level of measured crimes in STAR-active precincts to the contemporaneous change in comparison precincts (i.e., those where STAR services were unavailable). A key identifying assumption of this design is that the time-varying changes within the comparison precincts provide a valid counterfactual for what would have happened in the treated districts in the absence of treatment. We examine the empirical validity of this assumption in two ways. One is to estimate "event study" DD specifications that unrestrictively allow for effects unique to treatment precincts in each month. 
The event-study estimates indicate the extent to which the treatment and comparison precincts had similar month-to-month variation in STAR-related crimes before the pilot began (see the Supplementary Materials for details). If treatment and comparison precincts have similar trends in STAR-related crimes in the months before STAR operations, then it would be consistent with the internal validity of the DD design.

A second, important robustness check is to use Eq. 1 to estimate the impact of STAR operations on reports of more serious criminal offenses that are not directly related to STAR operations. If the estimates based on Eq. 1 are reliable, then we would expect the DD design to indicate that the effect of STAR operations on STAR-unrelated crimes is comparatively small, if not indistinguishable from zero. However, if DD estimates indicate that STAR operations had large effects on measured crimes unrelated to STAR, then it would suggest the existences of unobserved and confounding variables that are unique to the treated precincts in the treatment period. We formalize the idea of using the measured crimes unrelated to STAR operations as a comparison condition that is unique to each precinct and month in DDD specifications. Specifically, we stack the precinct-by-month data for these two crime categories $(n=864)$ and estimate the following specification

$$
\mathrm{Ypom}_{\mathrm{p}}=\alpha \mathrm{pm}+\gamma \mathrm{mo}+\delta_{\mathrm{po}}+\theta \mathrm{S}_{\mathrm{pom}}+\varepsilon \mathrm{pom}
$$

This specification includes unrestrictive fixed effects unique to each possible two-way interaction: precinct-month $(\alpha \mathrm{pm})$, month-offense $(\gamma \mathrm{mo})$, and precinct-

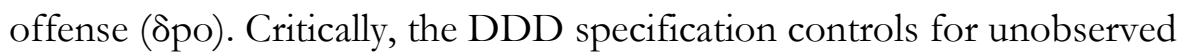
determinants of crime unique to each precinct-month combination. The parameter of interest reflects the estimated effect associated with the three-way interaction unique to STAR-related offenses observed in treated precincts during the treatment period (i.e., Spom). 


\section{REFERENCES AND NOTES}

1. C. Lum, D. S. Nagin, Reinventing American policing. Crime Justice 46, 339393 (2017).

2. C. F. Manski, D. S. Nagin, Assessing benefits, costs, and disparate racial impacts of confrontational proactive policing. Proc. Natl. Acad. Sci. 114, 93089313 (2017).

3. S. N. Durlauf, Assessing racial profiling. Econ. J. 116, F402-F426 (2006).

4. National Academies of Sciences, Medicine and Engineering, Proactive Policing: Effects on Crime and Communities. (National Academies Press, Washington, DC, 2018).

5. A. Irwin, B. Pearl, The community responder model: How cities can send the right responder to every 911 call. Center for American Progress, 2020.

6. S. R. Neusteter et al., Understanding police enforcement: A multicity 911 analysis. Vera Institute of Justice, 2020.

7. C. Lum, C. S. Koper, X. Wu, Can we really defund the police? A nine-agency study of police response to calls for service. Police Q. 10986111211035002 (2021), p. 3.

8. M. A. Cohen, A. R. Piquero, New evidence on the monetary value of saving a high risk youth. J. Quant. Criminol. 25, 25-49 (2009).

9. M. Jagannathan, "As activists call to defund the police, mental-health advocates say 'the time is now' to rethink public safety," MarketWatch, 19 June 2020.

10. M. G. McDowell, L. A. Fernandez, 'Disband, disempower, and disarm': Amplifying the theory and practice of police abolition. Critical Criminol. 26, 373-391 (2018).

11. US Department of Health \& Human Services, Mental Health Myths and Facts (2017); www.mentalhealth.gov. [accessed 8 January 2022]. 
12. M. E. Rueve, R. S. Welton, Violence and mental illness. Psychiatry 5, 34-48 (2008).

13. "Responding to persons experiencing a mental health crisis" (IACP Law Enforcement Policy Center, 2018).

14. D. A. Fuller, H. R. Lamb, M. Biasotti, J. Snook, Overlooked in the undercounted: The role of mental illness in fatal law enforcement encounters. Treatment Advocacy Center, 2015.

15. B. Dahlberg, "Rochester Hospital released Daniel Prude hours before fatal encounter with police," National Public Radio, 29 September 2020.

16. T. Elfrink, “"He’s a Small Child’: Utah Police Shot a 13-Year-Old Boy with Autism After His Mother Called 911 For Help” The W ashington Post, 8 September 2020 .

17. "Walter Wallace Jr. struggled with mental health issues, family says," NBC 10 Philadelphia, 29 October 2020.

18. C. Lum, Perspectives on policing: Cynthia Lum. Annu. Rev. Criminol. 4, 19-25 (2021).

19. M. T. Compton, M. Bahora, A. C. Watson, J. R. Oliva, A comprehensive review of extant research on Crisis Intervention Team (CIT) programs. J.Amer. Academy of Psychiatry Law Online 36, 47-55 (2008).

20. G. K. Shapiro et al., Co-responding police-mental health programs: A review. Adm. Policy Ment. Health 42, 606-620 (2015).

21. M. S. Morabito, J. Savage, L. Sneider, K. Wallace, Police response to people with mental illnesses in a major US city: The Boston experience with the coresponder model. Vict. Offenders 13, 1093-1105 (2018).

22. C. White, D. Weisburd, A co-responder model for policing mental health problems at crime hot spots: Findings from a pilot project. Policing: A Journal of Policy and Practice 12, 194-209 (2018). 
23. S.M. Yang, C. Gill, L. C. Kanewske, P. S. Thompson, Exploring police response to mental health calls in a nonurban area: A case study of Roanoke County, Virginia. Vict. Offenders 13, 1132-1152 (2018).

24. S. Puntis et al., A systematic review of co-responder models of police mental health 'street' triage. BMC Psychiatry 18, 1-11 (2018).

25. J. Peterson, J. Densley, Is Crisis Intervention Team (CIT) training evidencebased practice? A systematic review. J.Crime Justice 41, 521-534 (2018).

26. S. A. Taheri, Do crisis intervention teams reduce arrests and improve officer safety? A systematic review and meta-analysis. Crim. Justice Policy Rev. 27, 7696 (2016).

27. C. Seo, B. Kim, N. E. Kruis, Variation across police response models for handling encounters with people with mental illnesses: A systematic review and meta-analysis. J. Crim. Justice, 101752 (2020), p. 12.

28. C. Seo, B. Kim, N. E. Kruis, A meta-analysis of police response models for handling people with mental illnesses: Cross-country evidence on the effectiveness. International Crim. Justice Rev., 1-21 (2020).

29. T. Richards, "AOC's defund-the-police pick for NYC mayor will 'embolden the bad guys,' Kerik warns," The Washington Examiner, 8 June 2021.

30. R. J. Sampson, S. W. Raudenbush, Systematic social observation of public spaces: A new look at disorder in urban neighborhoods. Am. J. Sociol. 105, 603-651 (1999).

31. T. L. Meares, T. R. Tyler, J. Gardener, Lawful or fair-how cops and laypeople perceive good policing. J. Crim. Law Criminol. 105, 297-344 (2015).

32. J. Q. Wilson, G. L. Kelling, Broken windows. Atlantic Monthly 249, 29-38 (1982).

33. C. S. Koper, E. Mayo-Wilson, Police strategies to reduce illegal possession and carrying of firearms: Effects on gun crime. Campbell Syst. Rev. 8, 1-53 (2012). 
34. "Senator Wyden to visit CAHOOTS, citing as a model for reform" (White Bird Clinic, 2020).

35. "Gentrification study: Mitigating involuntary displacement" (City and County of Denver, 2016).

36. C. Herring, D. Yarbrough, L. Marie Alatorre, Pervasive penality: How the criminalization of poverty perpetuates homelessness. Soc. Probl. 67, 131-149 (2020).

37. T. Gowan, Hobos, Hustlers, and Backsliders: Homeless in San Francisco (Univ. of Minnesota Press, Minneapolis, MN, 2010).

38. T. Gowan, The Nexus: Homelessness and incarceration in two American cities. Ethnography 3, 500-534 (2002).

39. D. Mitchell, The Right to the City: Social Justice and the Fight for Public Space (Guilford Press, New York, 2003).

40. "Press release: DJP helps launch alternative public health emergency response pilot in Denver” (Denver Justice Project, 2020).

41. “STAR program evaluation,” Denverite, 8 January, 2021.

42. N. W. Link, J. T. Ward, R. Stansfield, Consequences of mental and physical health for reentry and recidivism: Toward a health-based model of desistance. Criminol. 57, 544-573 (2019).

43. D. T. O'Brien, C. Farrell, B. C. Welsh, Broken (windows) theory: A metaanalysis of the evidence for the pathways from neighborhood disorder to resident health outcomes and behaviors. Soc. Sci. Med. 228, 272-292 (2019).

44. J. A. Hausman, B. H. Hall, Z. Griliches, Econometric models for count data with an application to the patents-R\&D relationship. Econometrica 52, 909-938 (1984).

45. Y. Xu, Generalized synthetic control method: Causal inference with interactive fixed effects models. Polit. Anal. 25, 57-76 (2017). 
46. W. R. Shadish, T. D. Cook, D. T. Campbell, Experimental and QuasiExperimental Designs for Generalized Causal Inference (Houghton Mifflin, Boston, 2002).

47. S. D. Johnson, K. Bowers, A. Hirschfield, New insights into the spatial and temporal distribution of repeat victimization. Br. J. Criminol 37, 224-241 (1997).

48. J. Peterson, J. Densley, G. Erickson, Evaluation of 'The R-Model' crisis intervention de-escalation training for law enforcement. The Police Journal 93, 271-289 (2020).

49. J. Hails, R. Borum, Police training and specialized approaches to respond to people with mental illnesses. Crime Delinq. 49, 52-61 (2003).

50. E. Schmelzer, "Call police for a woman who is changing clothes in an alley? A new program in Denver sends mental health professionals instead," The Denver Post, 6 September 2020.

51. J. E. Pustejovsky, E. Tipton, Small-sample methods for cluster-robust variance estimation and hypothesis testing in fixed effects models. J. Bus. Econ. Stat. 36, 672-683 (2018). 
Acknowledgments: We thank Jeremy Pyne for generating the maps presented in this paper, Dagoberto Cortez for guidance on relevant urban gentrification literature, Chris Richardson and Carleigh Sailon for helping us better understand the STAR program Denver, CO., and Matthew Lunn for helping us better understand how the City and County of Denver record and publicly report their incident-level crime data. Funding: No funding was used for this project. Author contributions: Authors contributed equally to this work. Competing interests: The authors declare that they have no competing interests. Data and materials availability: All data and code needed to evaluate the conclusions in the paper are available at https://osf.io/y5jwg. 

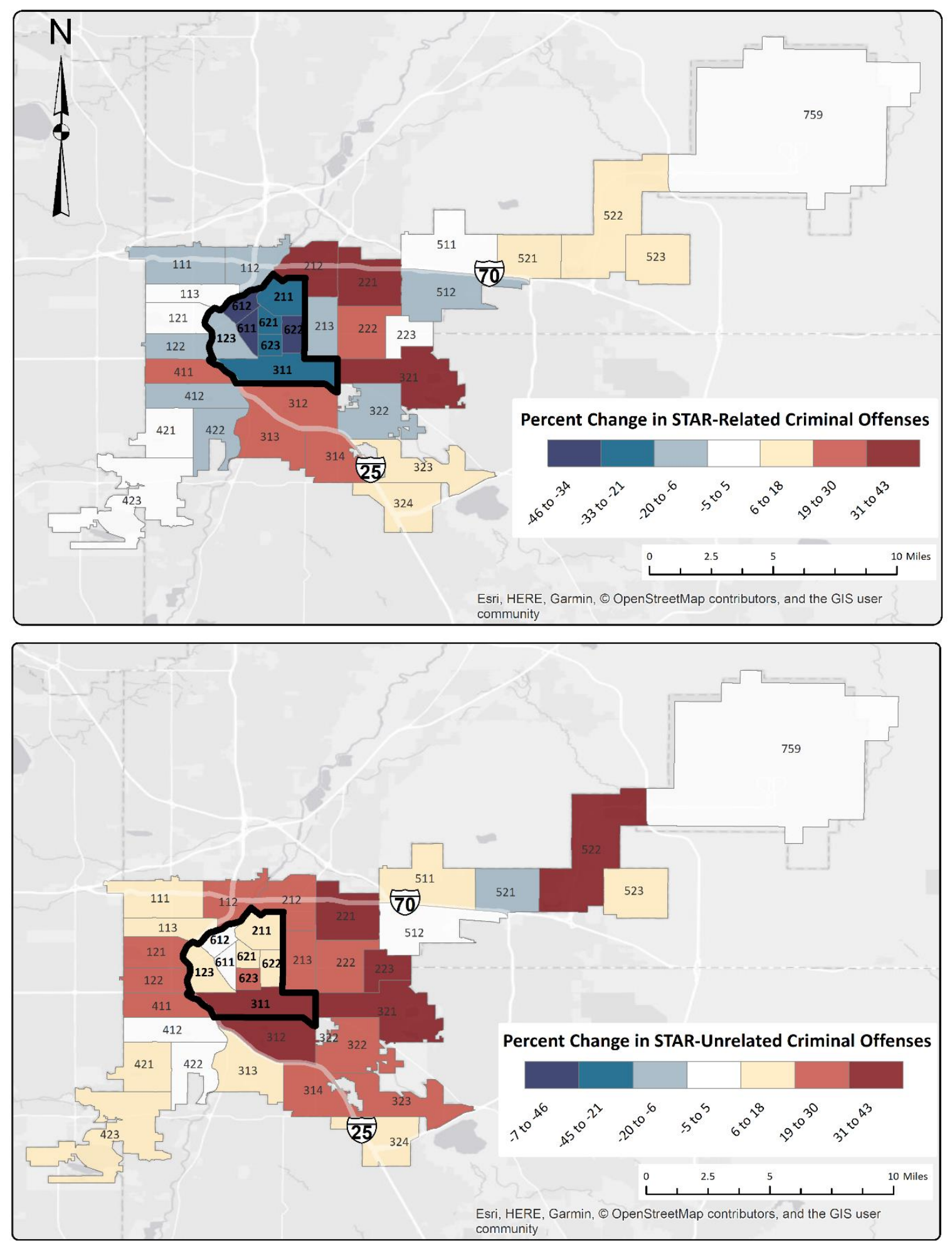

Fig. 1. Changes in criminal offenses before and after STAR pilot implementation. The thick black line surrounds the police precincts where the STAR program was active. 


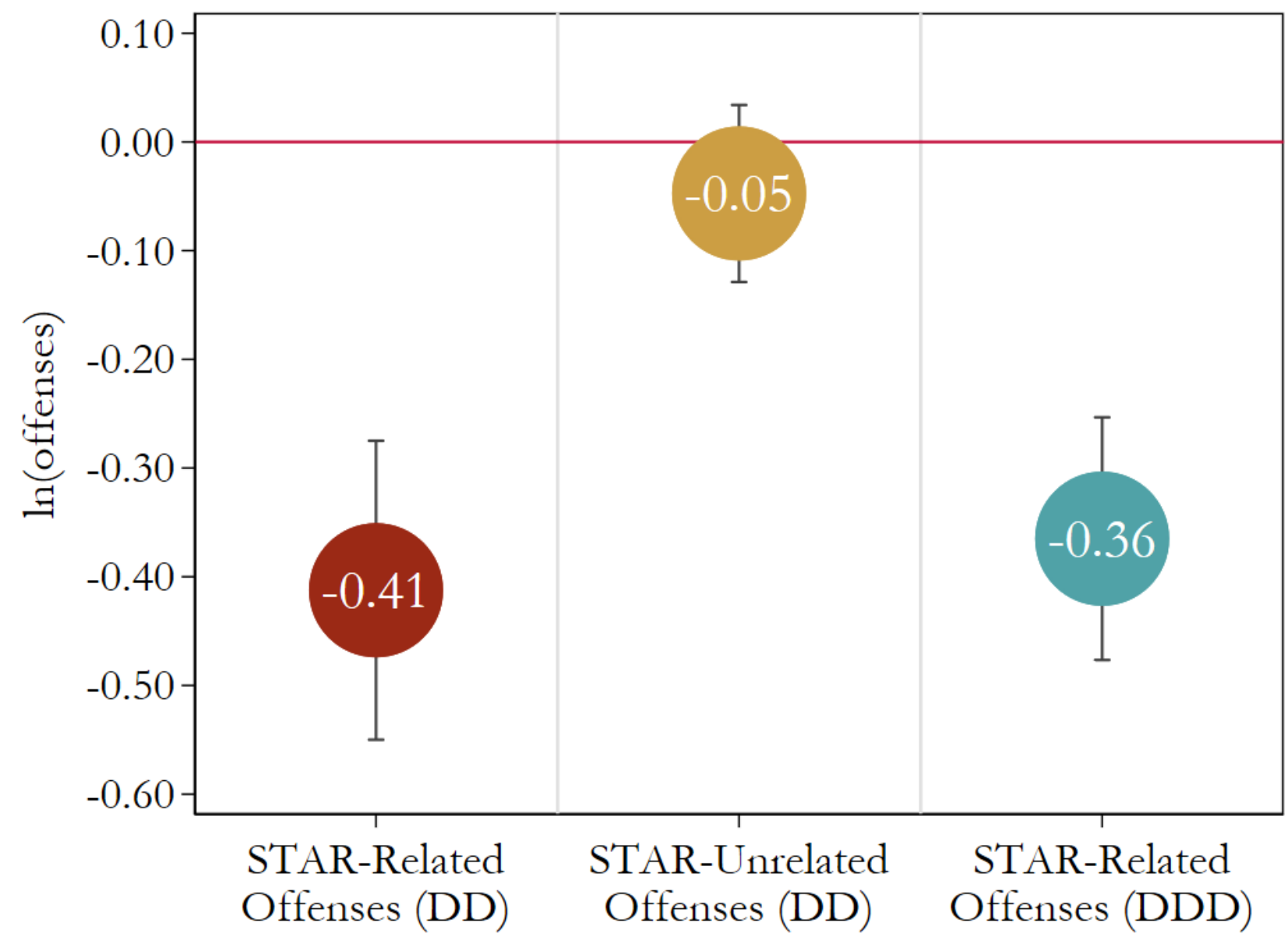

Fig. 2. Estimated effects of the STAR program on criminal offenses. The difference-indifferences (DD) estimates are based on 432 precinct-month observations and condition on precinct fixed effects and month fixed effects. The difference-in-difference-in-differences (DDD) estimates are based on the stacked precinct-month data for STAR and non-STAR offenses $(n=864)$. The DDD estimates condition on fixed effects unique to each category of the following 2-way interactions: precinct-by-month, precinct-by-STAR offense, and month-by-STAR offense. The outcome variables are the natural $\log$ of the offense counts. Dots are coefficients; bars are $95 \%$ confidence intervals. See Table S4 for numerical results. 


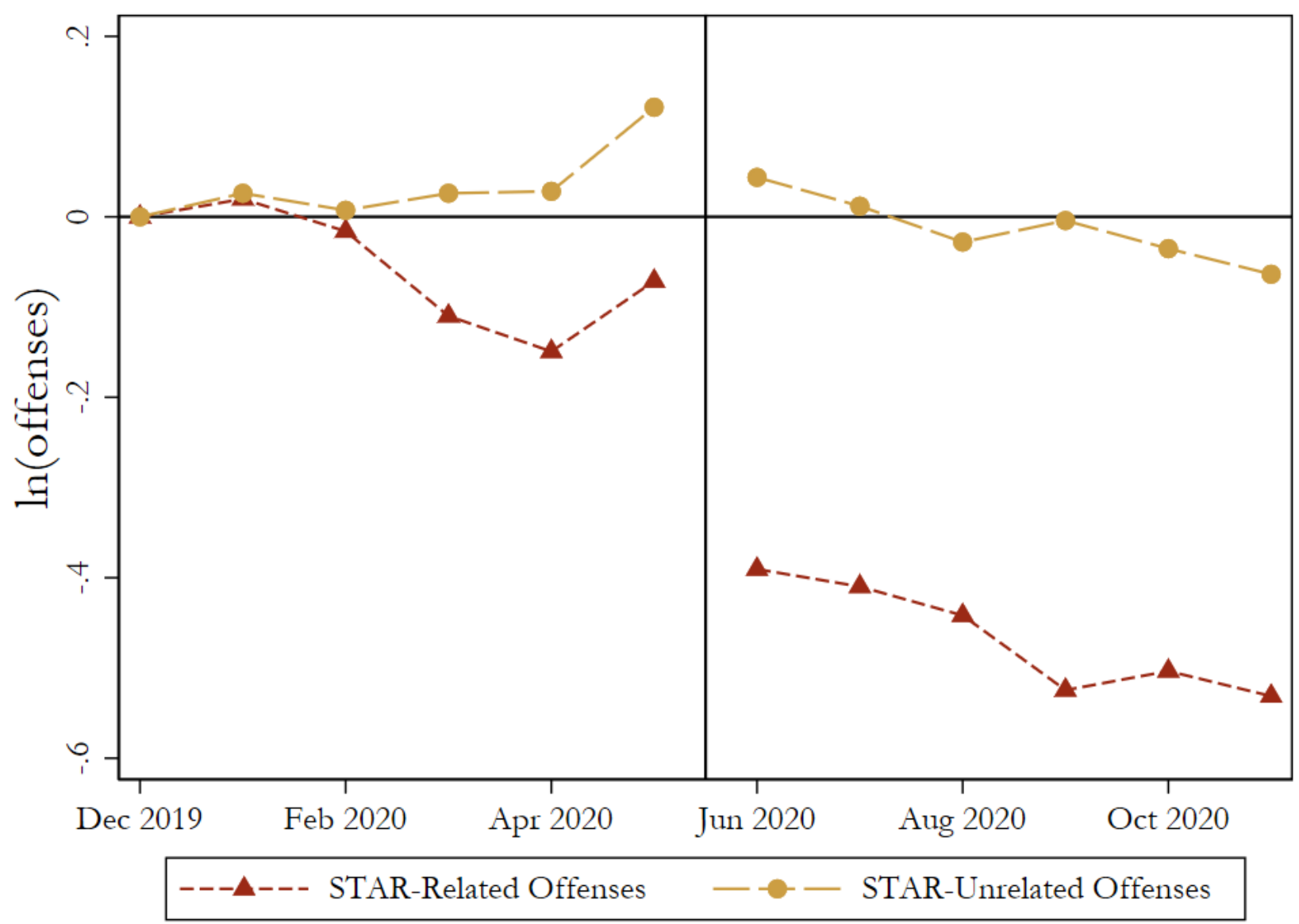

Fig. 3. Event study model. The difference-in-differences event-study (DD) estimates are based on 432 precinct-month observations and condition on precinct fixed effects and month fixed effects. The outcome variables are the natural $\log$ of the STAR-related and STAR-unrelated offense counts. The event-study estimates identify for each outcome the regression-adjusted treatment-comparison differences by month relative to the first time period (i.e., December 2019). The vertical line separates pre-treatment months from the months after the STAR pilot program began in June, 2020. See Table S5 for numerical results. 
Supplementary Materials 


\section{MATERIALS AND METHODS}

\section{City and Police Precinct Characteristics}

Figure S1 maps the police districts and neighborhoods in which the STAR program was active. The STAR pilot program operated in select police precincts, "from York St. to I-25 east to west and 38th St. / 40th Ave. to 6th Avenue north to south) and along the South Broadway corridor to Mississippi Ave., with service also being provided to the temporary shelters at the Denver Coliseum and National Western Complex" (25). This constitutes mainly the central downtown Denver area and includes police precincts 123, 211, 311, 611, 612, 621, 622, and 623 (see Figure S1). Table S1 presents descriptive demographic and socioeconomic data on these neighborhoods as well as for the entire city based on data from the American Community Survey (ACS). Denver, CO is a city with a population of 678,467 . In 2017 , the median household income was $\$ 59,179$ (15\% poverty). Just under half (46\%) had a bachelor's degree or higher, and the same proportion (46\%) are people of color.

\section{Sample Traits}

Table S2 shows the categorization of specific offenses in the City's NIBRS-based data as STAR-related or unrelated. Table S3 presents key descriptive statistics based on the precinct-month analytical sample $(\mathrm{n}=432)$. Specifically, this table shows the means for STAR-related and unrelated offenses (i.e., 33.7 and 156.0, respectively). It also shows the offenses across 10 broad and mutually exclusive categories of offenses used in the City's data file. Five uncommon categories of offenses unrelated to the STAR program's mission (i.e., arson, murder, robbery, sexual assault, white-collar offenses) are excluded.

\section{Offense Coding}

The incident data identify 199 types of offenses organized into 15 broader and mutually exclusive categories. For our primary analyses, we categorized each recorded offense by whether it was directly related to STAR services. Specifically, prior to our pre-registered analysis, two independent coders rated the categorization of each offense type. Raters had 91 percent agreement on offense type codes $(\mathrm{kappa}=0.73)$. Coders met and reconciled remaining discrepancies. The offenses identified as STAR-related include trespassing, disturbing the peace, possession of illegal drugs, indecent exposure, alcohol violations, loitering, failure to obey police orders, police interference, and public disorder. Prior to STAR operations, the offenses identified as STARrelevant offenses constituted 20 percent of the offenses reported by Denver police. As a complement to this binary categorization of offenses, we also show results based on broad, mutually exclusive categories the City reports.

\section{Treatment Heterogeneity and Evidence of Robustness}

The pre-registered "static" DD specification represented in equation [1] (see main text) assumes that the treatment effect is constant over time. However, the effects of the STAR program could instead have dynamic features. To test for time-varying treatment effects, we also employ a semi-dynamic DD model that unrestrictively allows for treatment effects unique to the month immediately after a precinct first participates and up to five months later:

$$
Y_{p m}=\alpha_{p}+\gamma_{m}+\sum_{n=0}^{5} \delta_{-n} S_{p, m-n}+\varepsilon_{p m}
$$

In this model, the three coefficients of interest are represented by $\delta_{n}$, which identify the effects of STAR in the first month of the program (i.e., $S_{p, m-0}$ ) as well as the current effect of having begun one 
month earlier (i.e., $S_{p, m-1}$ ), two months earlier (i.e., $S_{p, t m 2}$ ), and so on. We then test the equivalence of these coefficients of interest using the null hypothesis of a constant treatment effect:

$$
H_{0}: \delta_{0}=\delta_{-1}=\delta_{-2}=\delta_{-3}=\delta_{-4}=\delta_{-5}
$$

We report the semi-dynamic results, both for DD and DDD specifications, in Table S4. Hypothesis tests consistently fail to reject the null hypothesis of a common treatment effect across the 6-month pilot period.

The main text underscores two types of evidence consistent with the internal validity of the pre-registered DD results. One is the absence of a meaningful impact on offenses rated as unrelated to STAR prior to the analysis (i.e., column 3 in Table S4). Table S5 presents the results of a second and important type of evidence. A central and maintained identifying assumption of our pre-registered DD approach is that the month-to-month outcome changes among comparison precincts (i.e., those without a change in treatment status) provide a valid counterfactual for what would have changed for treatment precincts in the absence of treatment. This "parallel trends" assumption is fundamentally untestable. However, we can provide empirical evidence on the validity of this important assumption through unrestrictive "event study" specifications that allow us to examine whether treatment and comparison group precincts had similar month-to-month changes in outcomes prior to the onset of treatment. To the extent that this hypothesis is true, it is consistent with the parallel-trends assumption. We examine this question through event-study specifications of the following form:

$$
Y_{p m}=\alpha_{p}+\gamma_{m}+\sum_{\tau=1}^{5} \delta_{\tau} S_{p, m+\tau}+\sum_{n=0}^{5} \delta_{-n} S_{p, m-n}+\varepsilon_{p m}
$$

This event-study specification effectively extends the semi-dynamic specification (equation [2]) to allow for fixed effects unique to each month prior to participating in STAR (i.e., "leads" of treatment adoption). That means the coefficients of interest are represented as $\delta_{-n}$ and $\delta_{\tau}$, which designate the "effect" for precinct $p$ in month $m$ of participation in STAR $n$ months in the future or $\tau$ months in the past. The reference category includes those never participating in STAR and those in six months prior to their first participation in STAR. To examine the assumption of parallel trends, we test whether, prior to their participation in STAR, treatment precincts have month-to-month changes in outcomes distinct from comparison precincts:

$$
H_{0}: \delta_{5}=\delta_{4}=\delta_{3}=\delta_{2}=\delta_{1}=0
$$

We report the event-study results, both for STAR-related and unrelated offenses, in Table S5 and Figure 3 in the main text. The results are consistent with the parallel-trends assumption, indicating that we cannot reject the null hypothesis that the treated precincts had month-to-month changes similar to the comparison districts in the months prior to the program activity.

Table S6 presents the key results from a variety of alternative specifications that probe the robustness and heterogeneity of the confirmatory finding. First, we consider alternative approaches to conducting inference in this application. Our main estimates allow for precinct-specific clustering in the error term associated with criminal offenses that is heteroscedastic-consistent. However, because there are only 36 unique precincts, this clustering approach may be subject to finite-sample biases. To examine this concern, we report the results based on the procedure recently introduced by Pustejovsky and Tipton (51). The results are quite similar to our reported findings.

As a further and unrestrictive check on our main inference, we also conducted randomization inference with respect to the confirmatory finding. Specifically, over 100,000 replications, we randomly assigned treatment status within precincts and estimated the "impact" of the STAR 
program. Randomization inference has a particular appeal in applications like this because the data may be better understood as having "design-based" variation in what units are treated rather than having variation due to being drawn from a larger hypothesized population. Figure S4 shows the histogram of estimated effects based on this permutation procedure. Because treatment status was assigned randomly, this distribution can be understood as the distribution of treatment effects when the null hypothesis of no effect is true. Over the 100,000 replications, none of the estimates in this distribution was as large in absolute value as the estimate based on the actual data (i.e., -0.41). This implies a randomization-inference $p$-value that is less than 0.00001 .

Table S6 also presents results based on alternative estimation procedures and constructions of the analytical sample. Specifically, Table S6 presents the conditional maximum likelihood (CML) estimates of Poisson and negative binomial specifications that explicitly recognize both the count nature of the offense data and the presence of fixed effects (28). The resulting estimates are quite similar to those based on the pre-registered DD specification. Table S6 also presents the main DD results when dropping data from a STAR-participating police precinct (i.e., precinct 311) where program activities were targeted to a main corridor rather than intending to be active precinct-wide. Though there is no clear reason to expect biases from the onset of the COVID-19 pandemic, especially conditional on month fixed effects, Table S6 also shows the results of using data only from March 2020 (i.e., the onset of the shutdown) onward. Both data edits result in DD estimates consistent with our main finding.

Finally, Table S6 also presents the results of exploring two particular forms of treatment heterogeneity. First, we explored the possibility that the STAR program also led to crime reductions in geographically adjacent precincts. Specifically, we created an additional treatment indicator equal to one only for precincts that were adjacent to STAR precincts when the STAR program was active. The estimated effect reported in Table S6 indicates that we cannot reject the null hypothesis of no effect in neighboring precincts. We also explore possibly heterogeneous treatment effects across days of the week and times of the day when the STAR program was active. As the main text notes, the program was only active Monday through Friday, 10AM to 6PM. We created separate counts for STAR-related offenses that occurred within and outside these weekly windows. The results in Table S6 indicate that the STAR program led to similar reductions in targeted offenses across both time periods. As noted in the main text, this finding is consistent with the hypothesis that the program brought into the health-care system individuals in crisis who would otherwise commit police-reported offenses at other times of the week (i.e., evenings and weekends) as well. Table S7 reports results of DD estimates using generalized synthetic control (45) and comparative interrupted time series (CITS) designs (47), both of which are consistent with our main confirmatory findings.

Table S8 reports DD estimates of the impact of the STAR program on overall offenses and on offenses across the broad and mutually exclusive categories defined in the City's NIBRS-based data. The point estimates indicate that the STAR program reduced the natural log of total offenses by a statistically significant 0.15 , which implies the 14 percent reduction noted in the main text [i.e., $\left(e^{-0.15}\right.$ -1) $\times 100)$ ]. The estimates by category indicate that these reductions were plausibly concentrated in offenses such as "alcohol and drugs" (i.e., -0.53), "disorderly conduct" (i.e., -0.20), and "other crimes against people" (i.e., -0.14). 


\section{Pre-Registration Plan}

The following is our detailed pre-registration plan, filed on February 14, 2021 prior to any data analysis related to the study.

A. Study Information

\section{Hypotheses}

Precincts participating in the STAR program will have reduced prevalence of criminal offenses related to mental health, poverty, homelessness, and substance abuse in the City of Denver.

B. Design Plan

1. Study type

Observational Study - Data is collected from study subjects that are not randomly assigned to a treatment. This includes surveys, "natural experiments," and regression discontinuity designs.

\section{Blinding}

No blinding is involved in this study.

\section{Study design}

We focus on recorded offenses in each city precinct in a given month from December 1 , 2019 though November 30, 2020. This time period represents the six-month pilot phase of STAR (June 2020-November 2020) and the six months prior to the pilot beginning. This design strategy allows us to take advantage of our panel dataset in months surrounding implementation. Our analytical sample consists of 36 precincts and 432 precinct-month observations, from December 2019 through November 2020.

C. Sampling Plan

\section{Existing Data}

Registration prior to analysis of the data

\section{Explanation of existing data}

The data come from open access police records provided by the city of Denver, CO (https://www.denvergov.org/opendata/dataset/city-and-county-of-denver-crime). These data include criminal incident records from January 2, 2016 through January 15, 2021 involving adults. Due to legal restrictions, these data do not report crimes that by nature involve juveniles as victims (e.g., child abuse offenses), suspects or witnesses. These data also 
exclude "unfounded" incidents, which authorities have determined did not actually occur after they are reported.

\section{Data collection procedures}

We downloaded open access police records provided by the city of Denver, CO (https://www.denvergov.org/opendata/dataset/city-and-county-of-denver-crime). We retain recorded offenses in each city precinct in a given month from December 1, 2019 though November 30, 2020. This time period represents the six-month pilot phase of STAR (June 2020-November 2020) and the six months prior to the pilot beginning.

\section{Sample Size}

Our analytical sample consists of 36 precincts and 432 precinct-month observations, from December 2019 through November 2020.

\section{Sample size rationale}

This sampling allows for observation of criminal offenses in the city six months before and six months after the beginning of the STAR program, which allows for ample observation of pre and post treatment outcomes, tests of critical model assumptions, and for dynamic effects of the program.

D. Variables

\section{Measured variables}

Our outcome of interest is semi-logged precinct-month counts of STAR-related types of criminal offenses. The City of Denver codes recorded criminal offenses into fifteen overarching categories, including aggravated assault, arson, auto theft, burglary, drug and alcohol offenses, larceny, murder, public disorder, robbery, sexual assault, theft from motor vehicles, traffic accidents, white collar crimes, other crimes against individuals, and all other crimes. These categories give some sense of the types of crimes that might be related to the STAR programs aims but continue to carry a substantial amount of noise for our treatment estimates. From those 15 categories, offenses are differentiated by 199 different types. We coupled information on offense type descriptions and data on their frequencies with independent rater coding to identify those offenses that are STAR-relevant and those that are not. We measure treatment status by capturing each precinct's monthly participation in the STAR program. Using these data, we construct a simple binary indicator equal to 1 for precinct-month observations from precincts who participate in STAR during a given month (i.e., a "static" measure of treatment). We also use the timing of STAR participation to define less restrictive and flexibly dynamic measures of program participation. These include binary indicators for the month that the program began (June 2020) and separate indicators for being one through five months after that first participation month. These measures flexibly allow for the initial participation in STAR to have effects that increase or decline over time.

\section{Indices}


From the City of Denver's 15 overarching criminal offense categories, we differentiate those offenses that are most related to the types of calls that the STAR team will respond to from other types of offenses that are unlikely to either substitute for a noncriminal STAR team visit or would result from an escalation of such non-criminal offenses. From those 15 offense categories, offenses are differentiated by 199 different types. We coupled information on offense type descriptions and data on their frequencies with independent rater coding to identify those offenses that are STAR-relevant and those that are not.

E. Analysis Plan

\section{Statistical models}

Our main confirmatory analysis is based on a difference-in-differences (DD) design, which assumes that STAR activity in a given precinct and month leads to a constant, one-time change in STAR-related criminal offenses for participating precincts. We do so by comparing changes in these outcomes among precincts participating in STAR to outcomes of precincts that either never participated or had yet to participate in STAR. The outcome will be a semi-logged count of STAR-related criminal offenses. The predictors will be (1) an indicator of a treated precinct in a treated month, (2) precinct fixed effects, and (3) month fixed effects. Standard errors will be clustered at the precinct level.

\section{Transformations}

We use precinct-month counts of STAR-related criminal offenses in the panel data to estimate the effects of the STAR program on the number of offenses committed in each precinct. We transform the outcome variable, which is the semi-logged count of STARrelated criminal offenses for precinct $\mathrm{p}$ in month $\mathrm{m}$.

\section{Inference criteria}

We will make inferences of our confirmatory analysis using two-tailed tests and p-values of $\mathrm{p}<.10$. We will report $\mathrm{p}$-values differently based on thresholds of $\mathrm{p}<.01, \mathrm{p}<.05$, and $\mathrm{p}<.10$.

\section{Data exclusion}

We exclude data prior to December 2019 and after November 2020.

\section{Missing data}

There are no instances of missing precinct-month data, including criminal offenses recorded in a given precinct-month. Thus, we observe no missing data for our confirmatory analyses. However, in some exploratory analyses we examine program effects at the precinct-week level. For instances in which there are no STAR-related offenses in a given week, we will replace the missing value with the natural $\log$ of 0.5 . We do the same for STAR-unrelated offenses in exploratory analyses.

\section{Exploratory analysis}


We will conduct a number of exploratory analyses. First, to test for time-varying treatment effects, we next employ a semi-dynamic DD model that unrestrictively allows for treatment effects unique to the month immediately after a precinct first participates and up to seven months later. We then test the equivalence of these coefficients of interest using the null hypothesis of a constant treatment effect. Second, we will conduct an "event study" analysis. A crucial maintained assumption of our DD approach is that the month-to-month outcome changes among "control" precincts (i.e., those without a change in treatment status) provide a valid counterfactual for what would have changed for treatment precincts in the absence of treatment. This "parallel trends" assumption is fundamentally untestable. However, we can provide qualified evidence on the validity of this important assumption through unrestrictive "event study" specifications that allow us to examine whether treatment and control group precincts had similar month-to-month changes in outcomes prior to the onset of treatment. To the extent that this hypothesis is true, it is consistent with the parallel trends assumption. We examine this question through event-study specifications. Third, because these data also include counts of criminal offenses that are unrelated to the STAR programs goals, there is an opportunity to test a "triple diff' (DDD) research design that allows us to account for unobserved disturbances in precinct-month observations. Stacking our data at the precinctmonth-(STAR \& non-STAR) offense level, the DDD specification includes fixed effects for all two-way interactions. Fourth, we will rerun the static DD model for each of the 15 criminal offense category outcomes reported in the original dataset. Fifth, to test for potential differential effects of the COVID pandemic on criminal offenses, we rerun the confirmatory analysis but only include offenses from March 2020 through November 2020. Sixth, we rerun the confirmatory analysis using a count outcome in a negative binomial precinct fixed effects model. Seventh, we analyze the confirmatory outcome during STAReligible and STAR-ineligible times. Eighth, another model tests for spillover effects of the STAR program in precincts adjacent to the participating precincts. Ninth, we examine static and semi-dynamic program effects at the precinct-week level, for STAR-related and STARunrelated criminal offenses.

\section{Deviations from Pre-Registration Plan}

Our main results do not deviate from the pre-registration plan. However, we have added several additional exploratory analyses not reported in the original pre-registration plan. First, in a robustness check we recode "simple assaults", "simple assaults on police officers", and "disarming a piece officer" as STAR-unrelated offenses (see Table S6). Second, we include a static DD model in which we recode May 2020 as a "treatment" month among STAR-active precincts, to test for anticipation to the program's start (see Table S6). Third, in Table S5 we include an additional pretrends F-test for only months during COVID restrictions (i.e., March 2020 - May 2020). Fourth, we conduct placebo static DD and event study tests in years prior to our study window (see Table S6 and Figures S5-S7). Finally, we conduct additional robustness checks using a generalized synthetic control (GSC) design and a comparative interrupted time series (CITS) approach (see Table S7). 


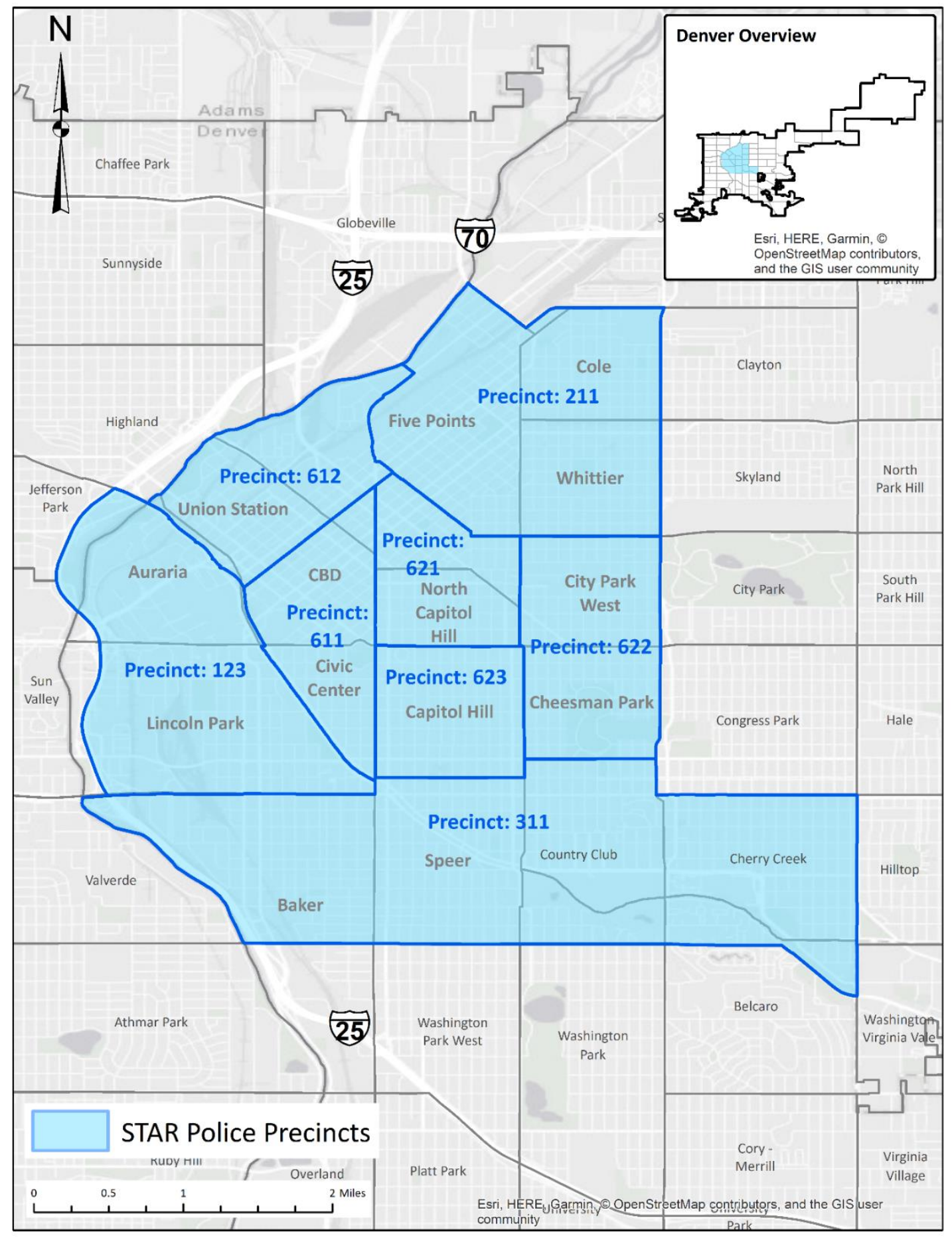

Figure S1. STAR police precincts and neighborhoods. Significantly affected police precincts and neighborhoods are bolded. 


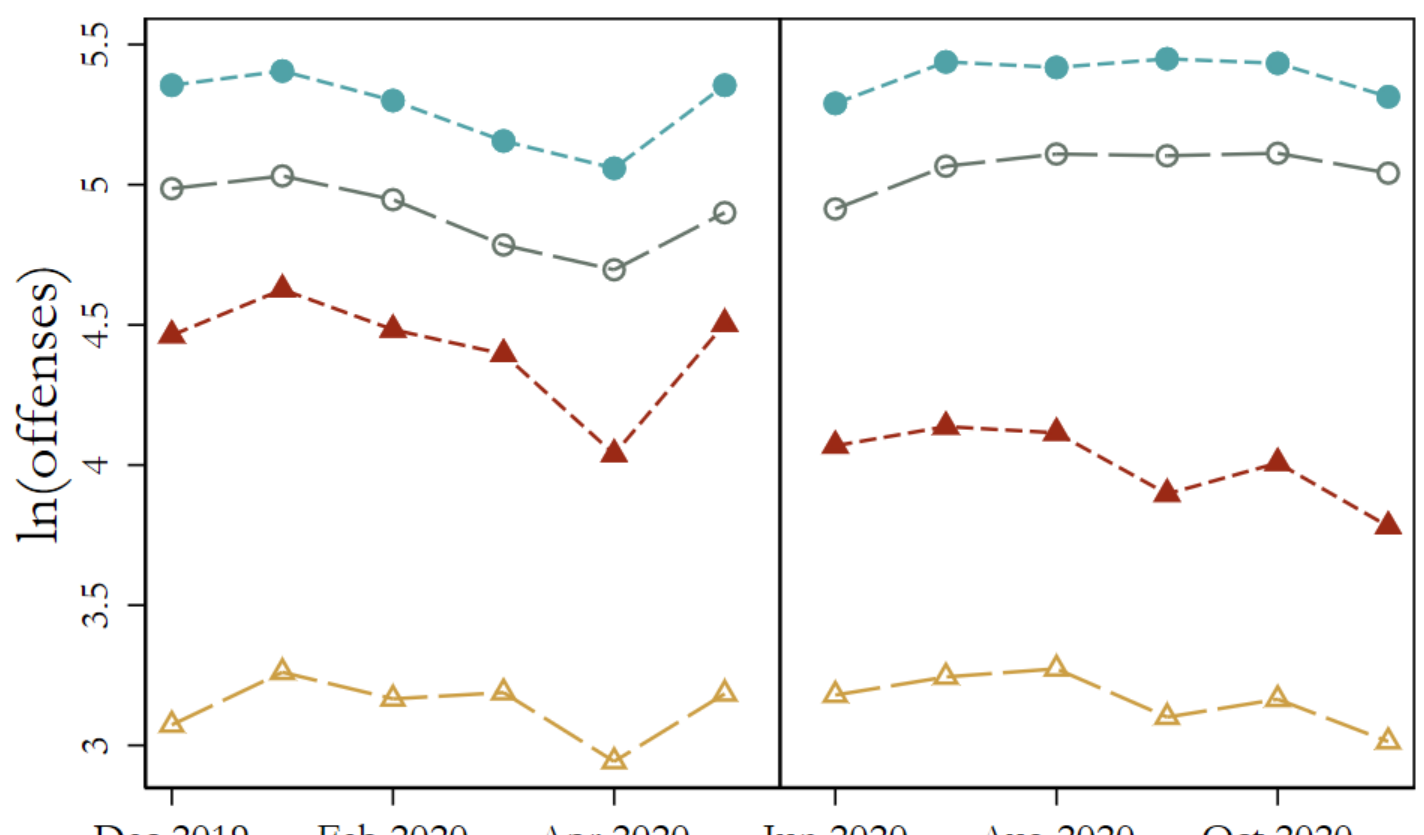

Dec 2019 Feb 2020 Apr 2020 Jun 2020 Aug 2020 Oct 2020

$$
\begin{aligned}
& ---\boldsymbol{-}--- \text { STAR Precincts, STAR-Related Offenses } \\
& --\triangle-\text { Other Precincts, STAR-Related Offenses } \\
& ---\bullet-- \text { STAR Precincts, STAR-Unrelated Offenses } \\
& -\bullet-\text { Other Precincts, STAR-Unrelated Offenses }
\end{aligned}
$$

Figure S2. Descriptive Monthly Trends in Offense Types. Conditional means of offenses are based on 432 precinct-month observations of all Denver police precincts, from December 2019 through November 2020. The outcome variables are the natural log of the offense counts, differentiated by STAR and non-STAR precincts as well as by STAR-related and unrelated offenses. The vertical line separates months before and after the STAR pilot program began. 


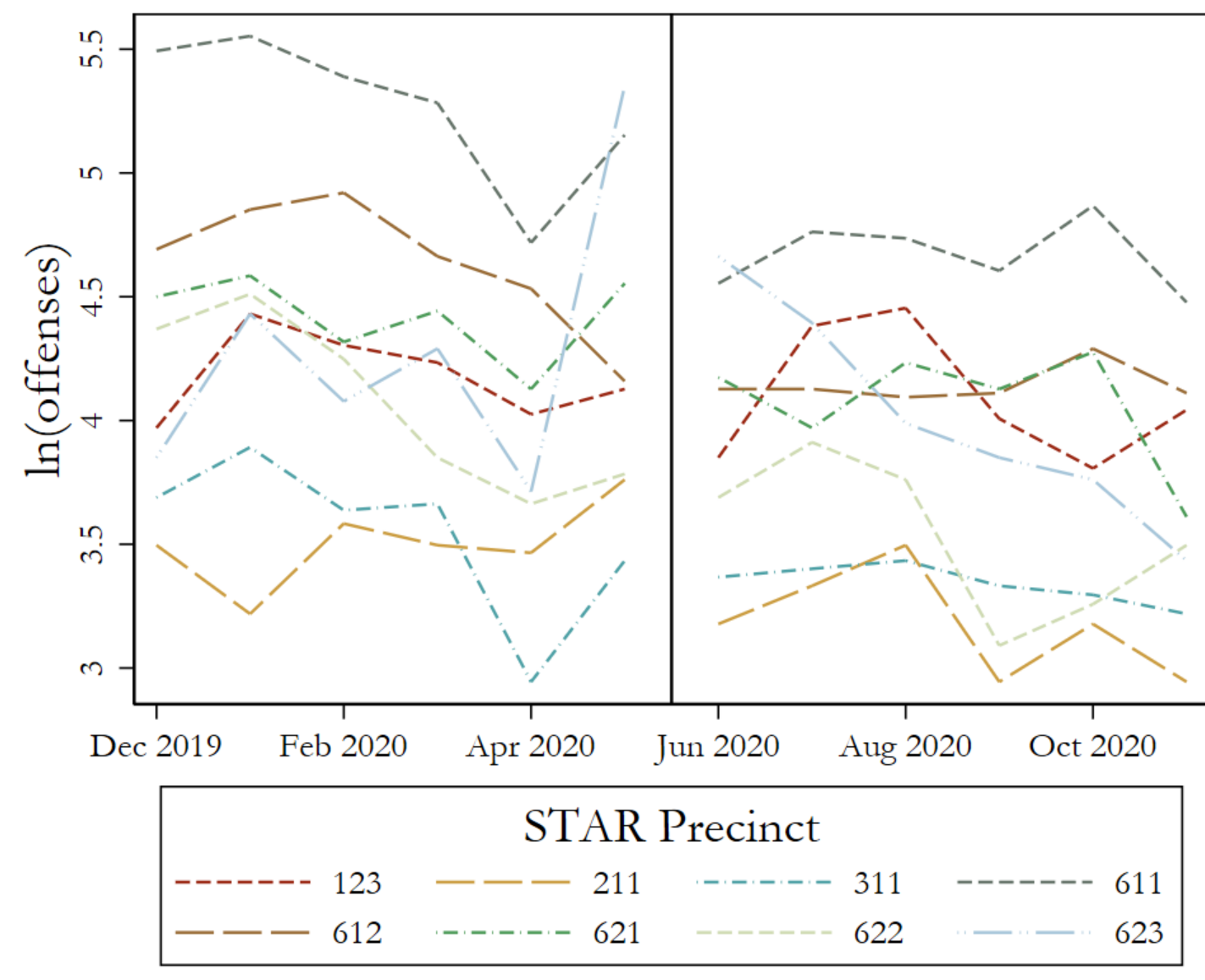

Figure S3. Descriptive Monthly Trends in STAR-Related Offenses among STAR Precincts. Lines are conditional means of STAR-related offenses based on 88 precinct-month observations from December 2019 through November 2020_one for each of the eight STAR-active precincts. The outcome variables are the natural log of the STAR-relevant offense counts. The vertical line separates months before and after the STAR pilot program began. 


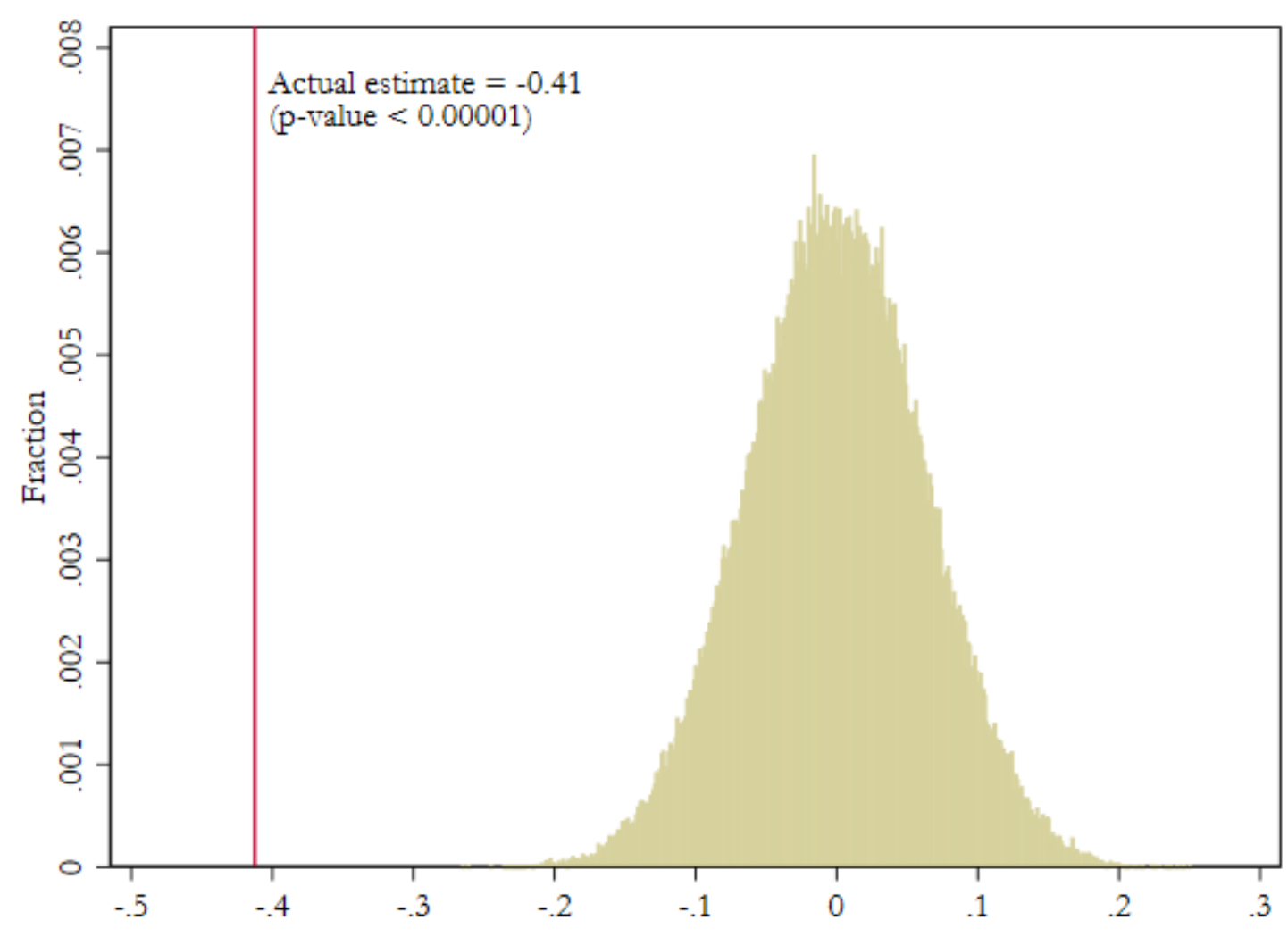

Figure S4. Null Distribution of Estimated Effects (100,000 Replications). Distribution represents results from 100,000 randomized simulations of the data under the assumption that the effects observed from the data were generated at random. The red vertical line represents the actual observed effect size from the data. 


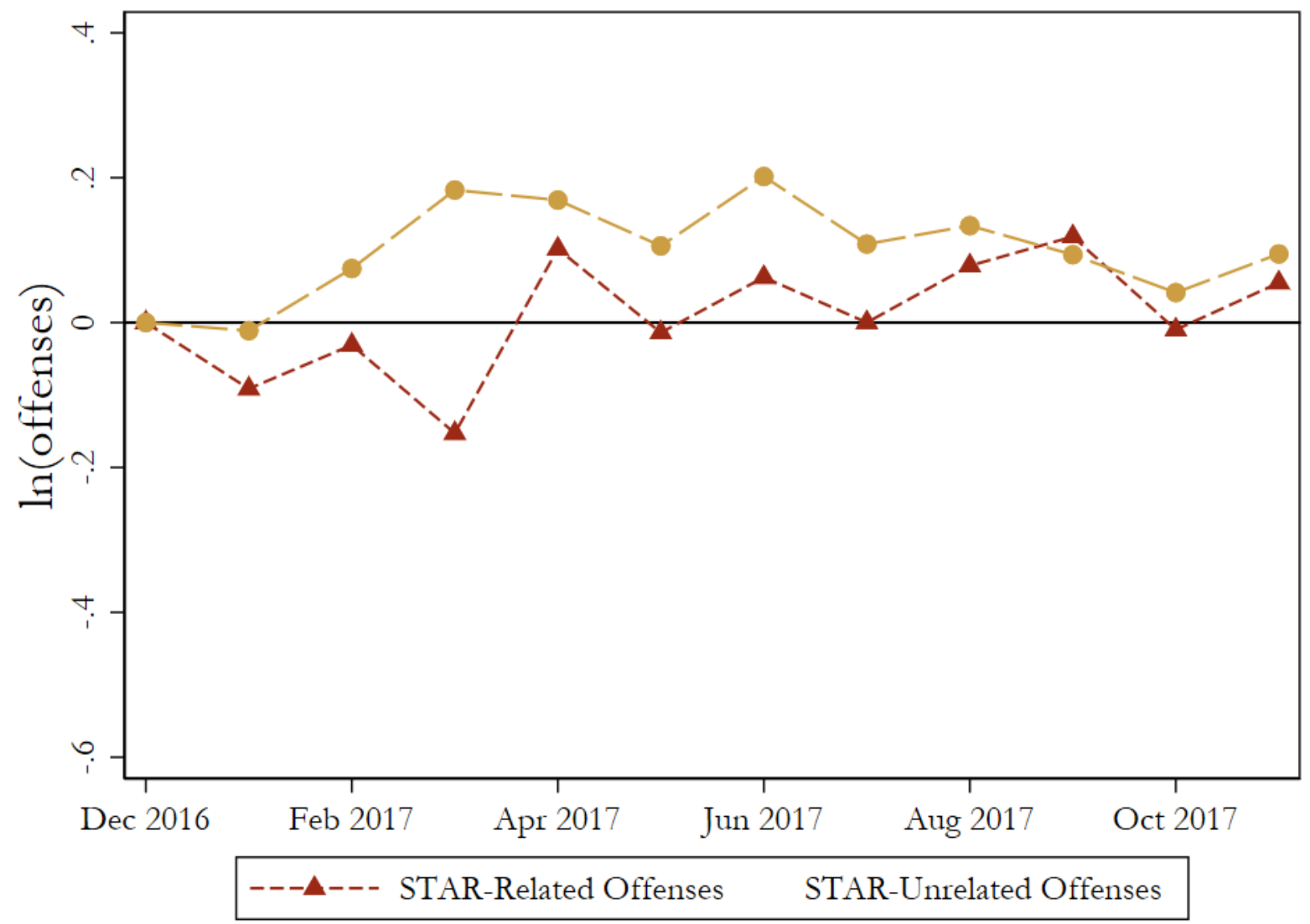

Figure S5. Placebo Event Study (Dec. 2016 - Nov. 2017). This placebo check mirrors the analyses represented in Figure 3 and Table S5, but applied to a time period other than our study window. Specifically, the difference-in-differences (DD) estimates are based on 432 precinct-month observations from December 2016 through November 2017 and condition on precinct fixed effects and month fixed effects. The outcome variables are the natural log of offense counts, differentiated by those that are STAR-related and those that are not. The horizontal line at zero denotes the baseline levels of offenses. 


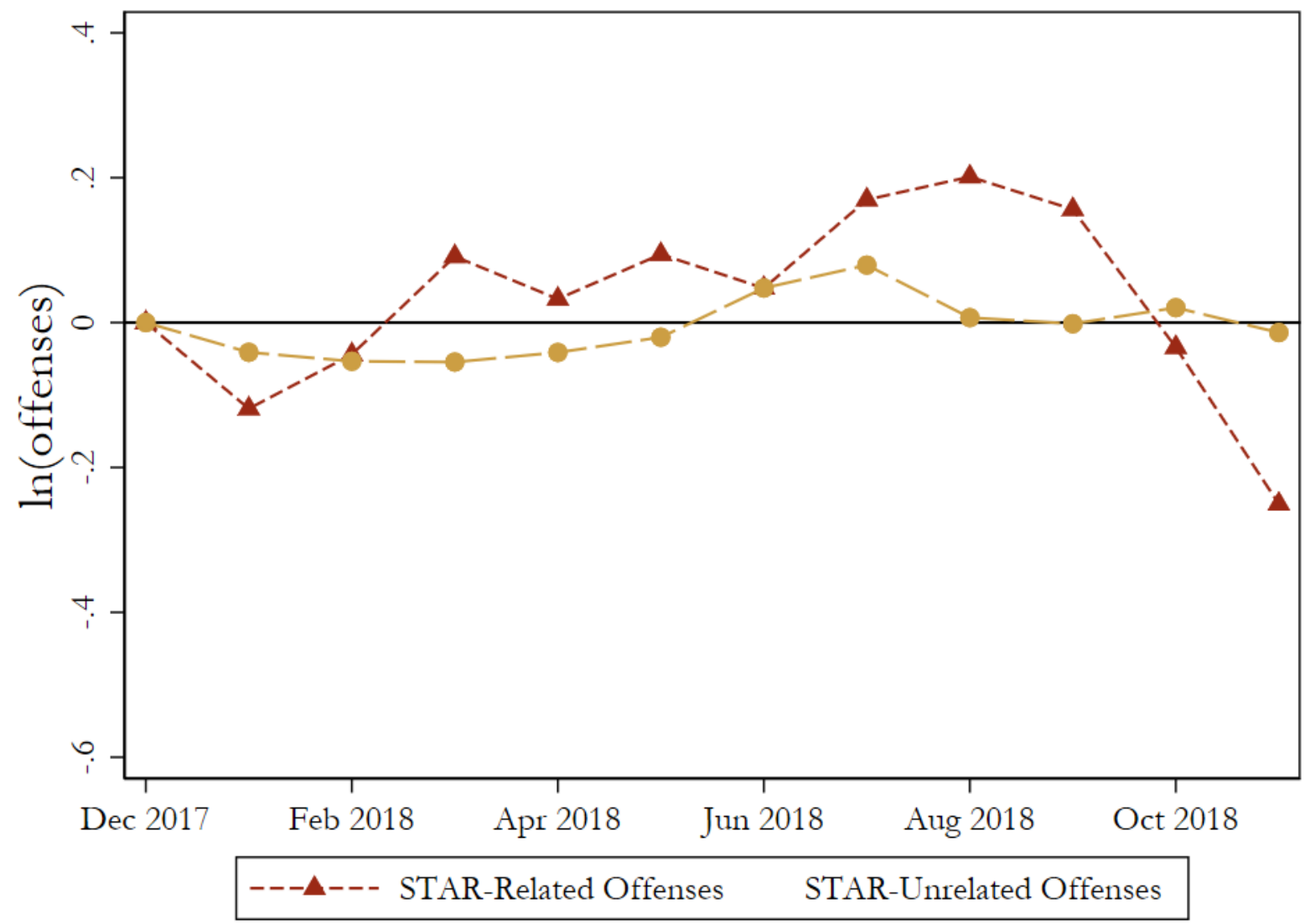

Figure S6. Placebo Event Study (Dec. 2017 - Nov. 2018). This placebo check mirrors the analyses represented in Figure 3 and Table S5, but applied to a time period other than our study window. Specifically, the difference-in-differences (DD) estimates are based on 432 precinct-month observations from December 2017 through November 2018 and condition on precinct fixed effects and month fixed effects. The outcome variables are the natural log of offense counts, differentiated by those that are STAR-related and those that are not. The horizontal line at zero denotes the baseline levels of offenses. 


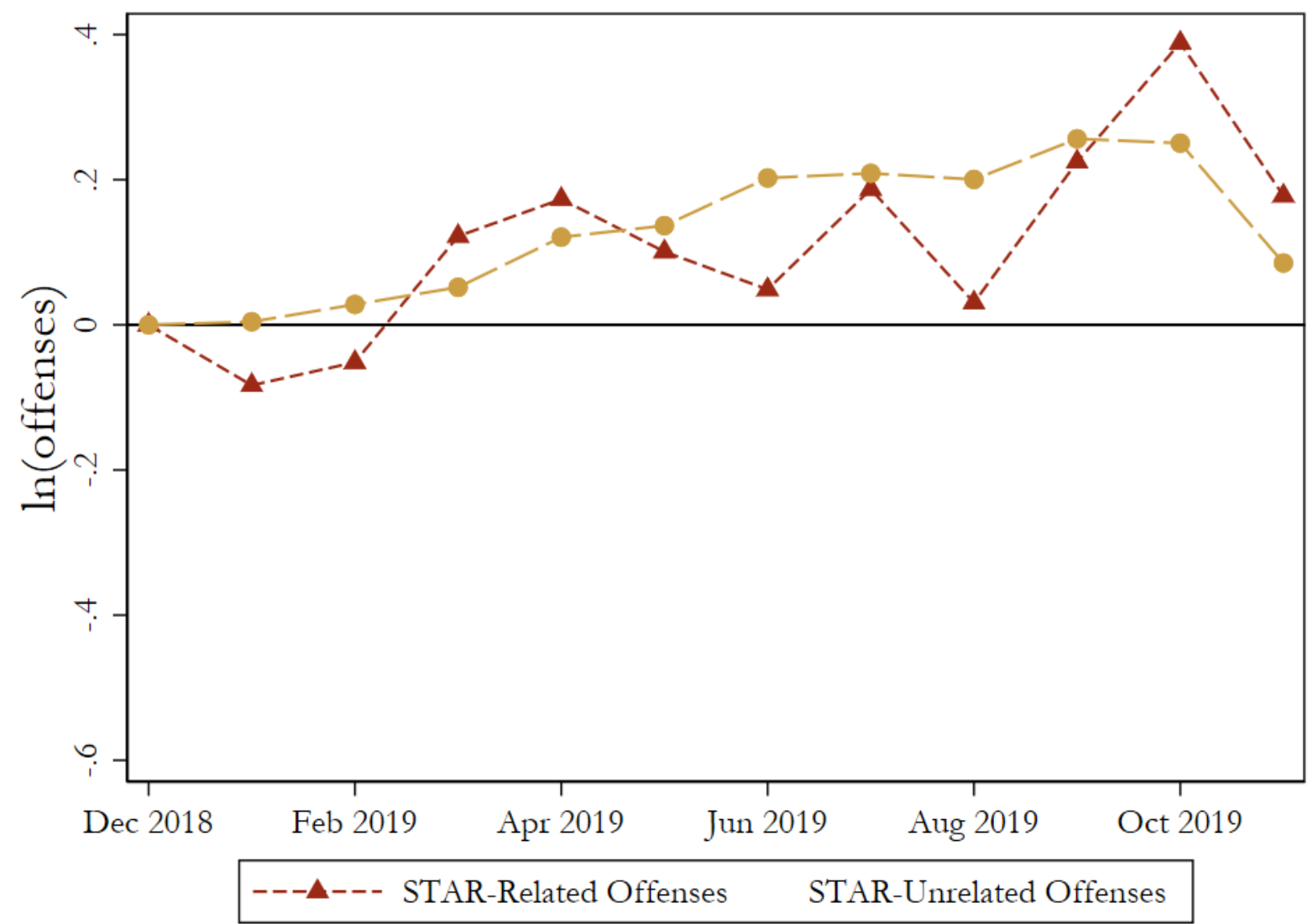

Figure S7. Placebo Event Study (Dec. 2018 - Nov. 2019). This placebo check mirrors the analyses represented in Figure 3 and Table S5, but applied to a time period other than our study window. Specifically, the difference-in-differences (DD) estimates are based on 432 precinct-month observations from December 2018 through November 2019 and condition on precinct fixed effects and month fixed effects. The outcome variables are the natural log of offense counts, differentiated by those that are STAR-related and those that are not. The horizontal line at zero denotes the baseline levels of offenses. 


\begin{tabular}{|c|c|c|c|c|c|c|c|c|}
\hline \multirow[b]{2}{*}{ Neighborhood } & \multirow[b]{2}{*}{ Population } & \multirow{2}{*}{$\begin{array}{c}\% \\
\text { College } \\
\text { Degree }\end{array}$} & \multirow{2}{*}{$\begin{array}{c}\text { Median } \\
\mathrm{HH} \\
\text { Income }\end{array}$} & \multicolumn{5}{|c|}{$\%$ People of Color } \\
\hline & & & & All & Black & Latinx & Asian & Other \\
\hline Auraria & 778 & $8 \%$ & $\$ 86,875$ & $30 \%$ & $1 \%$ & $23 \%$ & $0 \%$ & $6 \%$ \\
\hline Baker & 6,568 & $53 \%$ & $\$ 75,973$ & $35 \%$ & $4 \%$ & $24 \%$ & $2 \%$ & $5 \%$ \\
\hline Capitol Hill & 9,309 & $64 \%$ & $\$ 63,532$ & $14 \%$ & $2 \%$ & $6 \%$ & $2 \%$ & $4 \%$ \\
\hline CBD & 6,916 & $27 \%$ & $\$ 38,888$ & $62 \%$ & $13 \%$ & $44 \%$ & $2 \%$ & $3 \%$ \\
\hline Cheesman Park & 5,339 & $51 \%$ & $\$ 60,514$ & $32 \%$ & $11 \%$ & $14 \%$ & $3 \%$ & $4 \%$ \\
\hline City Park West & 4,552 & $26 \%$ & $\$ 63,250$ & $63 \%$ & $14 \%$ & $47 \%$ & $0 \%$ & $2 \%$ \\
\hline Civic Center & 18,924 & $46 \%$ & $\$ 70,971$ & $39 \%$ & $15 \%$ & $16 \%$ & $2 \%$ & $7 \%$ \\
\hline Cole & 12,061 & $63 \%$ & $\$ 66,120$ & $18 \%$ & $2 \%$ & $10 \%$ & $4 \%$ & $3 \%$ \\
\hline Five Points & 3,032 & $67 \%$ & $\$ 197,813$ & $8 \%$ & $1 \%$ & $3 \%$ & $0 \%$ & $3 \%$ \\
\hline Lincoln Park & 16,304 & $60 \%$ & $\$ 54,762$ & $23 \%$ & $4 \%$ & $11 \%$ & $4 \%$ & $4 \%$ \\
\hline North Capitol Hill & 6,754 & $60 \%$ & $\$ 69,668$ & $26 \%$ & $6 \%$ & $16 \%$ & $2 \%$ & $2 \%$ \\
\hline Speer & 2,256 & $59 \%$ & $\$ 105,962$ & $25 \%$ & $9 \%$ & $10 \%$ & $5 \%$ & $2 \%$ \\
\hline Union Station & 4,491 & $47 \%$ & $\$ 75,323$ & $29 \%$ & $3 \%$ & $16 \%$ & $4 \%$ & $7 \%$ \\
\hline Whittier & 7,500 & $71 \%$ & $\$ 95,487$ & $17 \%$ & $1 \%$ & $5 \%$ & $9 \%$ & $2 \%$ \\
\hline All STAR & 104,784 & $48 \%$ & $\$ 72,870$ & $33 \%$ & $8 \%$ & $19 \%$ & $3 \%$ & $4 \%$ \\
\hline All Non-STAR & 573,683 & $36 \%$ & $\$ 77,596$ & $44 \%$ & $8 \%$ & $30 \%$ & $3 \%$ & $3 \%$ \\
\hline City-Wide & 678,467 & $46 \%$ & $\$ 59,179$ & $46 \%$ & $10 \%$ & $33 \%$ & $4 \%$ & $3 \%$ \\
\hline
\end{tabular}

Table S1. STAR Pilot Program Neighborhood Demographics. Data come from 2019 American Community Survey data, retrieved from https://www.denvergov.org/opendata/dataset/americancommunity-survey-nbrhd-2015-2019. All the listed neighborhoods except Whittier are characterized as "displacement-vulnerable." 


\begin{tabular}{|c|c|c|c|c|}
\hline \multicolumn{5}{|c|}{ STAR-Related Offenses } \\
\hline Simple assault on police & Possession of cocaine & Possession of synthetic narcotic & Loitering & Property crimes - other \\
\hline Simple Assault & Possession of hallucinogenic drug & False imprisonment & Obstructing government operation & Public fighting \\
\hline Criminal mischief - other & Possession of heroin & Harassment & Failure to obey police order & Public order offense - other \\
\hline Criminal trespassing & Possession of marijuana & Harassment of a sexual nature & Giving police false information & Public peace - other \\
\hline Disarming a peace officer & Possession of methamphetamine & Indecent exposure & Police interference & Reckless endangerment \\
\hline Disturbing the peace & Possession of opium or derivative & Liquor law violation - other & Obstructing criminal investigation & Threatening to injure \\
\hline \multicolumn{5}{|c|}{ STAR-Unrelated Offenses } \\
\hline $\begin{array}{l}\text { Accessory/conspiracy to } \\
\text { crime }\end{array}$ & Selling cocaine & $\begin{array}{l}\text { Fraud by check due to } \\
\text { insufficient funds }\end{array}$ & Inciting a riot & Pocket picking \\
\hline & Forgery to obtain drugs & Gambling - betting or wagering & Robbery of a bank & Purse snatching without force \\
\hline Aggravated assault & Fraud to obtain drugs & Running a gambling operation & Robbery of a business & Shoplifting \\
\hline $\begin{array}{l}\text { Aggravated assault - domestic } \\
\text { violence }\end{array}$ & $\begin{array}{l}\text { Manufacture of hallucinogenic } \\
\text { drug }\end{array}$ & Gambling - gaming operation & Carjacking - armed & Theft of construction equipment \\
\hline Altering VIN number & Selling of hallucinogenic drug & Harassment - domestic violence & Forcible purse snatching & Theft of trailer \\
\hline $\begin{array}{l}\text { Possession of dangerous } \\
\text { animal }\end{array}$ & Selling of heroine & Stalking - domestic violence & Robbery of a person in a residence & $\begin{array}{l}\text { Unauthorized use of credit/debit } \\
\text { card }\end{array}$ \\
\hline Arson of a business & $\begin{array}{l}\text { Manufacture/sell other dangerous } \\
\text { drugs }\end{array}$ & Conspiracy to commit homicide & Robbery of a person in the open & Habitual traffic offender \\
\hline Arson - other & Cultivation of marijuana & Homicide by a family member & Unlawful sexual contact & Impound abandoned vehicle \\
\hline Arson to a public building & Selling of marijuana & Homicide by negligence & Rape & Traffic - other \\
\hline Arson of a residence & Selling of methamphetamine & Homicide by other means & Rape by person in position of trust & Vehicular assault \\
\hline Arson of a vehicle & Manufacture of methamphetamine & $\begin{array}{l}\text { Homicide of a police officer with } \\
\text { a gun }\end{array}$ & Sexual assault with an object & Vehicular homicide \\
\hline $\begin{array}{l}\text { Aggravated assault to police } \\
\text { using gun }\end{array}$ & $\begin{array}{l}\text { Selling of opium or an opium } \\
\text { derivative }\end{array}$ & Illegal dumping & Sexual assault - position of trust & Traffic accident \\
\hline Assault - domestic violence & Other dangerous drugs - PCS & Impersonation of a police officer & Sexual assault - fondling adult & Traffic accident - DUI DUID \\
\hline Bomb threat & Selling a synthetic narcotic drug & Intimidation of a witness & Sexual assault - non rape & Traffic accident - hit and run \\
\hline Bribery & Eavesdropping & Kidnap an adult & Sodomy of adult using force & Vehicular eluding \\
\hline $\begin{array}{l}\text { Burglary/auto theft of a } \\
\text { business }\end{array}$ & Escape of a prisoner & Domestic violence kidnapping & Failure to register as sex offender & Vehicular eluding - no chase \\
\hline $\begin{array}{l}\text { Burglary and auto theft at a } \\
\text { business - forced entry }\end{array}$ & Aiding the escape of a prisoner & Manufacture of liquor & Sex offender registration violation & Violation of court order \\
\hline $\begin{array}{l}\text { Burglary and auto theft at } \\
\text { residence }\end{array}$ & Possession of an explosive device & Liquor - misrepresenting age & Buy, sell, receive stolen property & Violation of custody order \\
\hline $\begin{array}{l}\text { Burglary and auto theft at a } \\
\text { residence - forced entry }\end{array}$ & Use of an explosive device & Illegal sale of liquor & Theft of bicycle & Violation of restraining order \\
\hline $\begin{array}{l}\text { Burglary of a business - forced } \\
\text { entry }\end{array}$ & Possession of explosive device & Littering & Theft by confidence game & Altering weapon serial number \\
\hline Burglary of a business & Extortion & $\begin{array}{l}\text { Threatening to injure with } \\
\text { weapon }\end{array}$ & Embezzlement by an employee & Possession of weapon \\
\hline Possession of burglary tools & Failure to report abuse & Money laundering & Failure to return rental vehicle & Carrying concealed weapon \\
\hline $\begin{array}{l}\text { Burglary of a residence - } \\
\text { forced entry }\end{array}$ & Possession of fireworks & Manufacture of obscene material & Theft from a building & Carrying prohibited weapon \\
\hline Burglary of a residence & Forgery of checks & Possession of obscene material & Theft from a mailbox & $\begin{array}{l}\text { Weapon fired into occupied } \\
\text { building }\end{array}$ \\
\hline Burglary of a safe & Counterfeiting an object & $\begin{array}{l}\text { Other environmental or animal } \\
\text { offense }\end{array}$ & Theft from a yard & Weapon fired into occupied vehicle \\
\hline Burglary of a vending machine & Forgery - other & Parole violation & Theft of fuel by driving off & Flourishing a weapon \\
\hline $\begin{array}{l}\text { Smuggle contraband to a } \\
\text { prisoner }\end{array}$ & $\begin{array}{l}\text { Possession of forged credit/debit } \\
\text { card }\end{array}$ & Pawn broker violation & Theft of items from vehicle & Weapon violation - other \\
\hline Possession of contraband & Possession of a forged instrument & making a false report to police & Theft of cable services & Possession of illegal weapon \\
\hline Criminal mischief - graffiti & $\begin{array}{l}\text { Possession of a counterfeiting } \\
\text { device }\end{array}$ & Probation violation & Theft of motor vehicle & Unlawful discharge of weapon \\
\hline $\begin{array}{l}\text { Criminal mischief to a motor } \\
\text { vehicle }\end{array}$ & Fraud by telephone & Aiding the act of prostitution & Theft of rental property & Unlawful sale of weapon \\
\hline Curfew violation & Fraud by use of computer & Engaging in prostitution & Theft of services & Window peeping \\
\hline Manufacture of a barbiturate & Criminal impersonation & Pimping for prostitution & Theft - other & Wiretapping \\
\hline Selling a barbiturate & Identity theft & Engaging in a riot & Theft of parts from a vehicle & Cruelty to animals \\
\hline
\end{tabular}

Table S2. Offense Type Codes Differentiated by STAR-Related and STAR-Unrelated

offenses. Offenses were differentiated using two independent coders who interpreted STAR guidelines for dispatching clinicians to mental-health and substance-abuse calls. 


\begin{tabular}{|c|c|c|c|c|c|}
\hline Variable & Mean & $\mathrm{SD}$ & Minimum & Maximum & $\begin{array}{c}\text { Percent } \\
\text { STAR- } \\
\text { Related } \\
\text { Offenses }\end{array}$ \\
\hline Active STAR Program & 0.11 & 0.31 & 0 & 1 & 25.1 \\
\hline STAR-related offenses & 33.7 & 30.9 & 5 & 258 & 100 \\
\hline STAR-unrelated offenses & 159.6 & 54.6 & 27 & 406 & 0.0 \\
\hline Total offenses & 193.3 & 75.3 & 48 & 606 & 21.1 \\
\hline \multicolumn{6}{|l|}{ Offenses by category } \\
\hline Alcohol and drugs & 6.3 & 7.6 & 0 & 64 & 69.8 \\
\hline Aggravated Assault & 6.8 & 4.9 & 0 & 26 & 0.0 \\
\hline Auto theft & 18.7 & 10.5 & 1 & 66 & 0.0 \\
\hline Burglary & 11.8 & 6.8 & 0 & 42 & 0.0 \\
\hline Disorderly conduct & 22.6 & 14.6 & 2 & 168 & 54.8 \\
\hline Larceny & 22.7 & 15.2 & 1 & 87 & 0.0 \\
\hline Theft from motor vehicle & 23.2 & 12.6 & 1 & 88 & 0.0 \\
\hline Traffic offenses & 35.7 & 19.0 & 1 & 119 & 0.0 \\
\hline Other crimes against people & 9.3 & 6.7 & 0 & 43 & 71.6 \\
\hline All other offenses & 28.8 & 24.9 & 1 & 204 & 35.5 \\
\hline
\end{tabular}

Table S3. Descriptive Statistics. The sample is based on Denver's 36 police precincts observed in each of 12 months from December 2019 through November 2020 (n = 432 precinct-month observations). Due to the very low instances of arson $(0.2 \%)$, murder $(0.1 \%)$, robbery $(2.8 \%)$, sexual assault $(1.5 \%)$, and white-collar offenses $(2.7 \%)$, we do not include those STAR-unrelated offense categories in the table. 


\begin{tabular}{|c|c|c|c|c|c|c|}
\hline \multirow[b]{3}{*}{ Independent Variables } & \multicolumn{4}{|c|}{$\mathrm{DD}$} & & \\
\hline & \multicolumn{2}{|c|}{$\begin{array}{c}\text { STAR-Related } \\
\text { Offenses }\end{array}$} & \multicolumn{2}{|c|}{$\begin{array}{c}\text { STAR- } \\
\text { Unrelated } \\
\text { Offenses }\end{array}$} & \multicolumn{2}{|c|}{ DDD } \\
\hline & $(1)$ & $(2)$ & (3) & (4) & $(5)$ & $(6)$ \\
\hline Active STAR program & $\begin{array}{c}-0.41 * * * \\
(0.07)\end{array}$ & & $\begin{array}{l}-0.05 \\
(0.04)\end{array}$ & & $\begin{array}{c}-0.36 * * * \\
(0.05)\end{array}$ & \\
\hline Adoption month: June 2020 & & $\begin{array}{c}-0.34 * * * \\
(0.12)\end{array}$ & & $\begin{array}{c}0.01 \\
(0.06)\end{array}$ & & $\begin{array}{c}-0.34 * * * \\
(0.09)\end{array}$ \\
\hline 1-month lag: July 2020 & & $\begin{array}{c}-0.36^{* * *} \\
(0.11)\end{array}$ & & $\begin{array}{l}-0.02 \\
(0.06)\end{array}$ & & $\begin{array}{c}-0.33^{* * *} \\
(0.10)\end{array}$ \\
\hline 2-month lag: August 2020 & & $\begin{array}{c}-0.39 * * * \\
(0.10)\end{array}$ & & $\begin{array}{l}-0.06^{*} \\
(0.04)\end{array}$ & & $\begin{array}{c}-0.32^{* * *} \\
(0.09)\end{array}$ \\
\hline 3-month lag: September 2020 & & $\begin{array}{c}-0.47 * * * \\
(0.11)\end{array}$ & & $\begin{array}{l}-0.04 \\
(0.05)\end{array}$ & & $\begin{array}{c}-0.43^{* * *} \\
(0.10)\end{array}$ \\
\hline 4-month lag: October 2020 & & $\begin{array}{c}-0.45^{* * *} \\
(0.08)\end{array}$ & & $\begin{array}{l}-0.07 \\
(0.06)\end{array}$ & & $\begin{array}{c}-0.38^{* * *} \\
(0.10)\end{array}$ \\
\hline 5-month lag: November 2020 & & $\begin{array}{c}-0.48^{* * *} \\
(0.11)\end{array}$ & & $\begin{array}{l}-0.10 \\
(0.06)\end{array}$ & & $\begin{array}{c}-0.38^{* * *} \\
(0.10)\end{array}$ \\
\hline$p$ value $\left(H_{o}: \delta_{0}=\delta-1=\delta-2=\delta_{-3}=\delta-4=\delta-5\right)$ & & 0.91 & & 0.68 & & 0.90 \\
\hline
\end{tabular}

Table S4. Estimated Effects of the STAR Program on Criminal Incidents. The difference-indifferences (DD) estimates are based on 432 precinct-month observations and condition on precinct fixed effects and month fixed effects. The difference-in-difference-in- differences (DDD) estimates are based on the stacked precinct-month data for STAR and non-STAR offenses $(n=864)$. The DDD estimates condition on fixed effects unique to each category of the following 2-way interactions: precinct-by-month, precinct-by-STAR offense, and month-by-STAR offense. The outcome variables are the natural $\log$ of the offense counts. Standard errors, clustered at the precinct level, are in parentheses. ${ }^{* * *} \mathrm{p}<0.01,{ }^{* *} \mathrm{p}<0.05, * \mathrm{p}<0.10$. 


\begin{tabular}{|c|c|c|}
\hline \multirow[b]{3}{*}{ Independent Variables } & \multicolumn{2}{|c|}{ Offense Type } \\
\hline & $\begin{array}{l}\text { STAR- } \\
\text { Related }\end{array}$ & $\begin{array}{c}\text { STAR- } \\
\text { Unrelated }\end{array}$ \\
\hline & (1) & (2) \\
\hline 5-month lead & $\begin{array}{c}0.02 \\
(0.12)\end{array}$ & $\begin{array}{c}0.03 \\
(0.05)\end{array}$ \\
\hline 4-month lead & $\begin{array}{l}-0.02 \\
(0.10)\end{array}$ & $\begin{array}{c}0.01 \\
(0.05)\end{array}$ \\
\hline 3-month lead & $\begin{array}{l}-0.11 \\
(0.12)\end{array}$ & $\begin{array}{c}0.03 \\
(0.07)\end{array}$ \\
\hline 2-month lead & $\begin{array}{l}-0.15 \\
(0.13)\end{array}$ & $\begin{array}{c}0.03 \\
(0.12)\end{array}$ \\
\hline 1-month lead & $\begin{array}{l}-0.07 \\
(0.24)\end{array}$ & $\begin{array}{c}0.12 \\
(0.13)\end{array}$ \\
\hline Precinct participated in June 2020 & $\begin{array}{c}-0.39 * * \\
(0.19)\end{array}$ & $\begin{array}{c}0.04 \\
(0.10)\end{array}$ \\
\hline Precinct participated in July 2020 & $\begin{array}{c}-0.41 * * \\
(0.17)\end{array}$ & $\begin{array}{c}0.01 \\
(0.09)\end{array}$ \\
\hline Precinct participated in August 2020 & $\begin{array}{c}-0.44 * * * \\
(0.16)\end{array}$ & $\begin{array}{l}-0.03 \\
(0.07)\end{array}$ \\
\hline Precinct participated in September 2020 & $\begin{array}{c}-0.52^{* * *} \\
(0.17)\end{array}$ & $\begin{array}{l}-0.00 \\
(0.08)\end{array}$ \\
\hline Precinct participated in October 2020 & $\begin{array}{c}-0.50 * * * \\
(0.13)\end{array}$ & $\begin{array}{l}-0.04 \\
(0.09)\end{array}$ \\
\hline Precinct participated in November 2020 & $\begin{array}{c}-0.53^{* * *} \\
(0.14)\end{array}$ & $\begin{array}{l}-0.06 \\
(0.08)\end{array}$ \\
\hline$p$ value $\left(H_{0}: \delta_{5}=\delta_{4}=\delta_{3}=\delta_{2}=\delta_{1}=0\right)$ & 0.71 & 0.87 \\
\hline$p$ value $\left(H_{0}: \delta_{3}=\delta_{2}=\delta_{1}=0\right)$ & 0.60 & 0.62 \\
\hline$p$ value $\left(H_{0}: \delta_{0}=\delta-_{1}=\delta_{-2}=\delta_{-3}=\delta-4=\delta-5\right)$ & 0.91 & 0.69 \\
\hline
\end{tabular}

Table S5. Event-study estimates. The difference-in-differences (DD) estimates are based on 432 precinct-month observations and condition on precinct fixed effects and month fixed effects. The outcome variables are the natural log of the STAR-related offense counts. Standard errors, clustered at the precinct level, are in parentheses. ${ }^{* * *} \mathrm{p}<0.01,{ }^{* *} \mathrm{p}<0.05,{ }^{*} \mathrm{p}<0.10$. 


\begin{tabular}{|c|c|}
\hline Model & $\begin{array}{c}\text { DD } \\
\text { Estimate }\end{array}$ \\
\hline Clustering corrected for finite sample bias & $\begin{array}{c}-0.41 * * * \\
(0.07)\end{array}$ \\
\hline Poisson fixed effects model & $\begin{array}{c}-0.45^{* * *} \\
(0.03)\end{array}$ \\
\hline Negative binomial fixed effects model & $\begin{array}{c}-0.42^{* * *} \\
(0.06)\end{array}$ \\
\hline Without Precinct $311(n=420)$ & $\begin{array}{c}-0.43^{* * *} \\
(0.07)\end{array}$ \\
\hline Post-pandemic months (March-Nov 2020) only $(n=324)$ & $\begin{array}{c}-0.38^{* * *} \\
(0.06)\end{array}$ \\
\hline Effects during STAR-eligible days and times & $\begin{array}{c}-0.37 * * * \\
(0.13)\end{array}$ \\
\hline Effects during STAR-ineligible days and times & $\begin{array}{c}-0.44 * * * \\
(0.06)\end{array}$ \\
\hline Recoding simple assaults as STAR-unrelated offenses & $\begin{array}{c}-0.49 * * * \\
(0.08)\end{array}$ \\
\hline Recoding May 2020 as a treatment month & $\begin{array}{c}-0.36^{* * *} \\
(0.09)\end{array}$ \\
\hline Effects in STAR-adjacent precincts (all times) & $\begin{array}{c}0.02 \\
(0.08)\end{array}$ \\
\hline Effects in STAR-adjacent precincts (eligible times) & $\begin{array}{l}-0.04 \\
(0.14)\end{array}$ \\
\hline Effects in STAR-adjacent precincts (ineligible times) & $\begin{array}{c}0.05 \\
(0.08)\end{array}$ \\
\hline Placebo effects, June - Nov. 2017 (Dec. 2016 start) & $\begin{array}{c}0.08 \\
(0.08)\end{array}$ \\
\hline Placebo effects, June - Nov. 2018 (Dec. 2017 start) & $\begin{array}{c}0.04 \\
(0.09)\end{array}$ \\
\hline Placebo effects, June - Nov. 2019 (Dec. 2018 start) & $\begin{array}{l}0.13 * \\
(0.05)\end{array}$ \\
\hline
\end{tabular}

Table S6. Alternative specifications. The difference-in-differences (DD) estimates are based on 432 precinct-month observations (unless otherwise noted). All models condition on month fixed effects. All models condition on precinct fixed effects. The outcome variables are the natural $\log$ of 
the STAR-relevant offense counts. Standard errors, clustered at the precinct level, are in parentheses. *** $\mathrm{p}<0.01,{ }^{* *} \mathrm{p}<0.05,{ }^{*} \mathrm{p}<0.10$. 


\begin{tabular}{|c|c|c|c|c|}
\hline & \multicolumn{2}{|c|}{ GSC } & \multicolumn{2}{|c|}{ CITS } \\
\hline & $\begin{array}{c}\text { STAR } \\
\text { Offenses }\end{array}$ & $\begin{array}{c}\text { Non- } \\
\text { STAR } \\
\text { Offenses }\end{array}$ & $\begin{array}{c}\text { STAR } \\
\text { Offenses }\end{array}$ & $\begin{array}{c}\text { Non- } \\
\text { STAR } \\
\text { Offenses }\end{array}$ \\
\hline Treatment X Post & $\begin{array}{c}-0.46^{* * *} \\
(0.14)\end{array}$ & $\begin{array}{c}0.02 \\
(0.11)\end{array}$ & $\begin{array}{c}-0.24^{* *} \\
(0.10)\end{array}$ & $\begin{array}{l}-0.03 \\
(0.05)\end{array}$ \\
\hline Treatment X Post X Trend & -- & -- & $\begin{array}{c}0.00 \\
(0.06)\end{array}$ & $\begin{array}{l}-0.04 \\
(0.03)\end{array}$ \\
\hline Treatment X Trend & -- & -- & $\begin{array}{l}-0.03 \\
(0.04)\end{array}$ & $\begin{array}{c}0.02 \\
(0.03)\end{array}$ \\
\hline
\end{tabular}

Table S7. Comparative interrupted time series estimates. The dependent variable is the natural $\log$ of the stated offenses ( $\mathrm{n}=432$ precinct-month observations). The first two columns report estimates based on generalized synthetic control (GSC; 45) and bootstrapped standard errors (1,000 replications). The next two columns report estimates based on a comparative interrupted time-series (CITS) specification (40) and standard errors clustered at the precinct level. The CITS specifications also condition on precinct fixed effects and month fixed effects. ${ }^{* * *} \mathrm{p}<0.01,{ }^{* *} \mathrm{p}<0.05,{ }^{*} \mathrm{p}<0.10$. 


\begin{tabular}{lc}
\hline & DD \\
Outcome Variable & Estimate \\
\hline \multirow{3}{*}{ All offenses } & $-0.15^{* * *}$ \\
& $(0.05)$ \\
Alcohol and drugs & $-0.53^{* *}$ \\
& $(0.20)$ \\
Aggravated Assault & 0.05 \\
Auto theft & $(0.15)$ \\
& $0.15^{*}$ \\
Burglary & $(0.09)$ \\
& -0.06 \\
Disorderly conduct & $(0.09)$ \\
Larceny & $-0.20^{* * *}$ \\
Theft from motor vehicle & $(0.06)$ \\
Traffic offenses & -0.06 \\
Other crimes against people & $(0.08)$ \\
All other offenses & 0.04 \\
& $(0.09)$ \\
& -0.04 \\
& $(0.06)$ \\
& $-0.14^{*}$ \\
& $(0.07)$ \\
& -0.13 \\
& $(0.12)$ \\
& \\
& \\
&
\end{tabular}

Table S8. Estimated Effects by Offense Category. The difference-in-differences (DD) estimates are based on 432 precinct-month observations and condition on precinct fixed effects and month fixed effects. Due to the very low instances of arson, murder, robbery, sexual assault, and white-collar offenses, we do not include those STAR-unrelated offense categories. The outcome variables are the natural $\log$ of the offense counts. Standard errors, clustered at the precinct level, are in parentheses. $* * * \mathrm{p}<0.01,{ }^{*} * \mathrm{p}<0.05, * \mathrm{p}<0.10$. 